\title{
El extractivismo y sus despliegues conceptuales*
}

\author{
Extractivism and its conceptual deployments
}

\author{
Rafael Domínguez Martín**
}

Resumen: El objetivo de este trabajo es analizar el despliegue y contenido conceptual del extractivismo desde su origen como modo de apropiación de los recursos naturales, estrategia de desarrollo dependiente y estilo de desarrollo insostenible, hasta llegar al rango de categoría para el análisis histórico de los procesos de acumulación por desposesión/apropiación que ha alcanzado en la actualidad y que lo convierten en ingrediente central del capitalismo y su ecología-mundo. La hipótesis, comprobada tras el análisis de la literatura, es que la genealogía marxista del extractivismo ha permitido esa ampliación de la cobertura analítica del concepto contra la intención original de su creador (Eduardo Gudynas). La conclusión del trabajo apela a reconstruir un Ruy Mauro Marini ecológico, mediante la integración de las teorías estructuralista y marxista de la dependencia en el marco de la súper-explotación del trabajo y la sobreexplotación de la naturaleza procedente de la tradición del marxismo ecológico en sus variantes latinoamericana y de la ecología-mundo.

Palabras clave: extractivismo, neo-extractivismo, acumulación, sobreexplotación de la naturaleza, ecología-mundo

\begin{abstract}
The objective of this work is to analyze the deployment and conceptual content of extractivism from its origin as a mode of appropriation of natural resources, dependent development strategy and unsustainable development style, until reaching the category rank for the historical analysis of the processes of accumulation by dispossession / appropriation that it has reached today and that make it a central ingredient of capitalism and its world-ecology. The hypothesis, proven after the analysis of the literature, is that the marxist genealogy of extractivism has allowed this expansion of the analytical coverage of the concept against the original intention of its creator (Eduardo Gudynas). The conclusion of the work appeals to rebuild an ecological Ruy Mauro Marini, through the integration of the structuralist and marxist theories of dependency within the framework of superexploitation of work and overexploitation of nature, from the tradition of ecological marxism tradition in its Latin American and world-ecology variants.
\end{abstract}

\footnotetext{
* El origen de este trabajo se remonta en las discusiones que mantuve con Alessandra Corrado mientras realizaba una consultoría para la CEPAL sobre "Recursos naturales extractivos e industrialización en los países andinos", en Santiago de Chile durante el verano de 2019. A la profesora Corrado, del Departamento de Ciencias Políticas y Sociales de la Università della Calabria, debo el conocimiento de la obra de Jason Moore. Una versión inicial del argumento se presentó en el seminario del mismo título impartido en el Instituto de Ciencias Sociales y Humanidades “Alfonso Vélez Pliego" de la Benemérita Universidad Autónoma de Puebla en noviembre de 2019. El texto ha sido actualizado con la bibliografía publicada hasta mediados de noviembre de 2020. Agradezco a Sara Caria (del Instituto de Altos Estudios Nacionales del Ecuador) la revisión y observaciones. Mi gratitud también para Esteban Valenzuela (del Departamento de Administración Pública y Ciencia Política de la Universidad de Concepción) por aceptar la versión íntegra del trabajo. Los errores y omisiones son de mi exclusiva responsabilidad.

** Doctor en Historia Económica, Catedrático de Historia e Instituciones Económicas, Cátedra COIBA, Departamento de Economía de la Universidad de Cantabria (España); domingur@unican.es. ORCID 0000-0002-5938-0023; http://unican.academia.edu/RafaelDomingur.
} 
Key words: extractivism, neo-extractivisim, accumulation, overexploitation of nature, world-ecology

Recibido: 16 septiembre 2020 Aceptado: 8 diciembre 2020

\section{Introducción}

El objetivo de este artículo es analizar el despliegue y contenido conceptual del extractivismo desde su origen como modo de apropiación de los recursos naturales, estrategia de desarrollo dependiente y estilo de desarrollo insostenible, hasta llegar al rango de categoría para el análisis histórico de los procesos de acumulación por desposesión/apropiación que ha alcanzado en la actualidad y que lo convierten en ingrediente central del capitalismo y su ecología-mundo. De este modo, se pueden distinguir dos tradiciones teóricas sobre el extractivismo, a las que consideramos posible integrar en razón de su común filiación marxista (Grigera y Álvarez, 2013): la tradición dependentista y de raíz latinoamericana, que agrupa el concepto de extractivismo como modo de apropiación de los recursos naturales, estrategia de desarrollo dependiente y estilo de desarrollo insostenible; y la tradición propiamente extractivista, de dominante norteamericana y europea, que identifica el extractivismo con los procesos continuos de acumulación por desposesión/apropiación del capitalismo.

Esta diferenciación, empero, resulta doblemente artificial. A nivel geográfico porque la tradición dependentista latinoamericana estuvo muy influida por el trabajo seminal del sociólogo norteamericano Stephen G. Bunker (1985) y su noción de "periferia extractiva organizada en respuesta a las demandas del mercado mundial" (Bunker, 1985: 60). Y a nivel teórico porque las dos tradiciones se solapan: el modo de apropiación es la precondición del modo de acumulación del extractivismo histórico, que se puede considerar un rasgo estructural de la historia económica de América Latina, tanto si se observa la larga duración (Schuldt y Acosta, 2006; Acosta 2009; 2011a; Galafassi, 2012; Machado, 2013; 2015) como si se circunscribe al período de la globalización neoliberal que se alumbró al final de la década de 1970 (Brand, Dietz y Lang, 2016; Teran, 2016; Svampa y Teran, 2019; Svampa, 2019), lo que permite unificar las perspectivas dependentistas y las de los modelos históricos de acumulación.

La hipótesis de trabajo es que la genealogía marxista del extractivismo es lo que ha permitido la ampliación de la cobertura analítica del concepto contra la intención original de su creador (Eduardo Gudynas). El marco del artículo integra diversos enfoques de economía y ecología política internacional bajo el paraguas de las teorías renovadas de la dependencia (en sus versiones estructuralista y marxista) y el marxismo ecológico, mientras que la revisión bibliográfica internacional sobre el extractivismo ha sido realizada a partir de una combinación del método histórico-estructural y de las reconstrucciones racional e histórica del pensamiento económico.

La estructura del ensayo se divide en tres secciones que abordan sucesivamente el extractivismo como modo de apropiación de los recursos naturales, como estrategia de desarrollo dependiente y estilo de desarrollo insostenible, y, por último, como núcleo central del capitalismo. El texto cierra con la apelación a reconstruir un Ruy Mauro Marini ecológico mediante la integración de las teorías estructuralista y marxista de la dependencia, haciendo pasar el concepto de competitividad espuria de Fernando Fajnzylber por el marco de la súper-explotación del trabajo y la sobreexplotación de la naturaleza procedente de la tradición del marxismo ecológico en sus variantes latinoamericana y de la ecología-mundo.

\section{Extractivismo como modo de apropiación de los recursos}


El extractivismo fue un término acuñado por el ecólogo social uruguayo Eduardo Gudynas en 2009 para diferenciar entre "los estilos de extractivismo promovidos por los gobiernos progresistas" -O neo-extractivismo, del que la Concertación por la Democracia en Chile fue el "caso pionero"- y "la persistencia del estilo extractivista... bajo gobiernos conservadores" (Gudynas, 2009: 188-190). Gudynas, que primero habló de "estilo de desarrollo basado en la apropiación de la Naturaleza" (Gudynas, 2009: 188), definió el extractivismo como "un tipo particular de extracción de recursos naturales, en gran volumen o alta intensidad, de los cuales el 50\% o más es destinado a la exportación, como materias primas sin procesar o con un procesamiento mínimo", sobre el entendido de que incluye no solo la explotación, sino las fase previas de exploración y descubrimiento y las fases posteriores de cierre y abandono de los sitios de apropiación (Gudynas, 2013: 15). Aunque desde un inicio Gudynas consideró el neo-extractivismo como una estrategia de desarrollo dependiente y un estilo de desarrollo insostenible (Gudynas, 2009; 2010a; 2011a; 2012a; 2012b; 2013), finalmente basó el énfasis de su definición de extractivismo en el concepto "modo de apropiación de los recursos" (Gudynas 2015: 17).

Si bien Gudynas prefiere hablar de modos de apropiación en plural, de extractivismos mineros y agrícolas concretos, "anclados a localizaciones específicas" y que funcionan no solo como "enclaves ecológicos" sino como "enclaves económicos" (Gudynas, 2019: 392), la concreción de la definición del modo de apropiación extractivista como tipo ideal se planteó de manera alusiva en términos de objetivos, estructura y esencia constitutiva: el objetivo del extractivismo sería la exportación de los recursos en forma de materias primas para los mercados internacionales; su estructura respondería a los primeros eslabones de las cadenas globales de valor, es decir, el modo de apropiación estaría conectado y articulado al modo de producción capitalista; mientras que la esencia consititutiva del extractivismo habría que buscarla en la "frontera de avance de la mercantilización del entorno" (Gudynas, 2015: 205). En definitiva, en el modo de apropiación extrativista, los recursos primarios serían "removidos para ser exportados, como insumos para distintas cadenas de producción" (Gudynas, 2015: 190), lo que presupone como condición necesaria la "mercantilización de la Naturaleza" (Gudynas, 2015: 176)1. Este modo de apropiación, por sus irreversibles impactos ambientales y elevados impactos sociales, así como por su lógica acumulativa, sería el responsable de la multiplicación de los conflictos socioambientales a medida que se producen "nuevas geografías extractivas" (Gudynas, 2018a: 67) como consecuencia de la "ofensiva extractivista" (Merchand, 2016: 176).

Las actividades extractivistas puden ser de extracción directa o indirecta/mediada, lo que trasciende la tradicional división entre recursos no renovables y renovables. En la extracción directa se produce la apropiación de los recursos en ambientes naturales o poco modificados para su utilización directa por los humanos, como es el caso de la minería, los hidrocarburos, la silvicultura y el sector pesquero. En la extracción indirecta/mediada es necesaria una transformación previa del ambiente natural a partir de la cual se obtienen los recursos, como es el caso del extractivismo agrario de monocultivos de exportación o cultivos flexibles (soja y biocombustibles), la piscicultura, las camaroneras y el turismo de masas (Gudynas, 2009; 2013; 2015; 2018a; Baletti, 2014; McKay, 2017; Córdoba et al., 2018).

Según Gudynas (2015), el extractivismo sería una categoría para el análisis histórico en América Latina que permite distinguir cuatro generaciones o fases. Así, el extractivismo actual (de tercera y cuarta generación) es el heredero del extractivismo de la Colonia o de primera generación, y del extractivismo del boom exportador de la globalización temprana (1870-1914), o de segunda generación. El extractivismo actual, por tanto, sería fruto de un continuum histórico marcado por el aumento del volumen, variedad e intensidad de los recursos apropiados. Ello responde a la ley de los rendimientos

\footnotetext{
${ }^{1}$ Para el caso de Chile, véase el excelente análisis sobre la mercantilización y neoliberalización del territorio en las regionescommodity de Bustos-Gallardo y Prieto (2019).
} 
decrecientes de los recursos no renovables o que, siendo en teoría renovables (tierras de cultivo, bosques y pesquerías), se extraen a tasas que no permiten renovar los stocks de nutrientes o las biomasas respectivas. El paso de cada una de las generaciones de extractivismo a la siguiente estaría marcado por el deterioro del balance energético (medido por el retorno energético de la inversión en energía, EROI por sus siglas en inglés). En la actualidad, dicho umbral se sitúa en 3 a 1, de modo que, por debajo de ese nivel, la mitad o más del recurso extraído se debe utilizar para obtener la energía necesaria para la siguiente extracción, que es lo que ocurre con la fractura hidráulica (la cuarta generación del extractivismo de los hidrocarburos), que, además de ser inviable desde el punto de vista social y ambiental, resulta muy costosa en términos económicos (Gudynas, 2015).

Todos los extractivismos, independientemente de su generación y variantes, tienen impactos ambientales negativos, por lo que desde la crítica al extractivismo es imposible aceptar el discurso del optimismo tecnológico de las industrias extractivas sobre el impacto cero de la minería verde o la supuesta sostenibilidad de los monocultivos de exportación. Las obras de acceso a los yacimientos mineros, la remoción física y selección de los recursos, las construcciones asociadas (escombreras o diques de relaves), o el cambio en los usos del suelo de los monocultivos de exportación tienen afectaciones graves sobre el agua, el suelo, el aire, el patrimonio ambiental y la biodiversidad. Estos impactos ambientales son, por definición, impactos sociales, ya que afectan a la salud, los derechos, y la calidad y el modo de vida de personas y comunidades. Toda la discusión sobre la gestión ambiental sostenible de las industrias extractivas (incluidas las evaluaciones de impacto ambiental) está viciada porque se centra exclusivamente en manejar o remediar los efectos secundarios de la extracción (las externalidades negativas sociales y ambientales), dejando de lado el impacto primario de la destrucción del patrimonio natural a sabiendas de que su remediación es imposible (Gudynas, 2015).

Esto se comprueba con la megaminería, lo que da lugar a una verdadera "amputación ecológica" (Gudynas, 2015: 52). La megaminería se refiere a aquellos proyectos en que se remueven más de un millón de toneladas de materia por año, incluyendo tanto el mineral como el material que no es utilizado o "mochila ecológica", y se afectan más de mil hectáreas de superficie (Gudynas, 2015: 14). La amputación ecológica es la remoción física de un ecosistema completo, que destruye no solo su entramado biológico (especies vivas) sino su basamento material. Gudynas usa el término "extrahección" para describir este tipo de proyectos de "extractivismo depredador" (Gudynas, 2013: 14). Tales proyectos representan "el caso más agudo de apropiación de recursos naturales, donde éstos son extraídos por medio de violencia y se incumplen los derechos humanos y de la Naturaleza", así que la extrahección es la "condición necesaria para poder llevar a cabo la apropiación de recursos naturales" (Gudynas, 2013: 14).

Por tanto, para imponer una verdadera protección ambiental, todas la manifestaciones del extractivismo depredador -la megaminería, la petrolización de zonas protegidas y parques nacionales, los monocultivos de exportación- deberían prohibirse. Ello se justifica por la irreversibilidad de los procesos de destrucción provocados por los efectos primarios de la extracción intensificada (directa en los dos primeros casos y mediada en el último). En cuanto a los efectos secundarios de la extracción, debería tenerse en cuenta la diversidad de externalidades que sistemáticamente son ignoradas por el análisis coste-beneficio que domina las evaluaciones de impacto ambiental (EIA), las cuales tienden a sobreestimar los impactos positivos (crecimiento de los ingresos y del empleo en la fase de construcción) y subestimar o eludir los impactos negativos sobre la calidad de vida y la biodiversidad. Uno de los aspectos clave en la sobreestimación de los impactos positivos sería la distorsión de la contabilidad convencional de los precios de las materias primas (Gudynas, 2009; 2015).

Finalmente, Gudynas recurre al concepto de "derrames" o "efectos derrame" del extractivismo, que, más allá de lo local, repercutirían en la gestión territorial, la dinámica económica y la inserción internacional, el papel del Estado, la calidad de las instituciones y hasta la propia concepción de la Naturaleza (Gudynas, 2015: 67). Uno de los elementos en los que se materializan esos tipos de derrames es la flexibilización ambiental, que consiste en "contar con estándares más bajos, tolerar 
excepcionalidades, o debilitar el control" (Gudynas, 2015: 76). Para ello se busca aligerar las exigencias ambientales a través de la conversión de las EIA en un mero trámite administrativo o el acotamiento y abaratamiento de las sanciones gubernamentales por determinados incumplimientos (Gudynas, 2015), a lo que se une el uso intensivo de "subsidios perversos", tales como incentivos fiscales, energía barata, y facilidades de acceso a infraestructura o comerciales (Gudynas, 2018c: 31). Además, la flexibilización ambiental es uno de los componentes clave de la carrera de mínimos o hacia el fondo (race to the bottom) que se aceleró tras el fin del boom de las materias primas en 2014. La carrera de mínimos es "un conjunto de políticas destinadas a atraer inversiones extractivas para compensar la caída de los precios mediante el relajamiento de estándares fiscales, ambientales y sociales” (Ballón et al., 2018: 14).

Figura 1. Carrera hacia el fondo

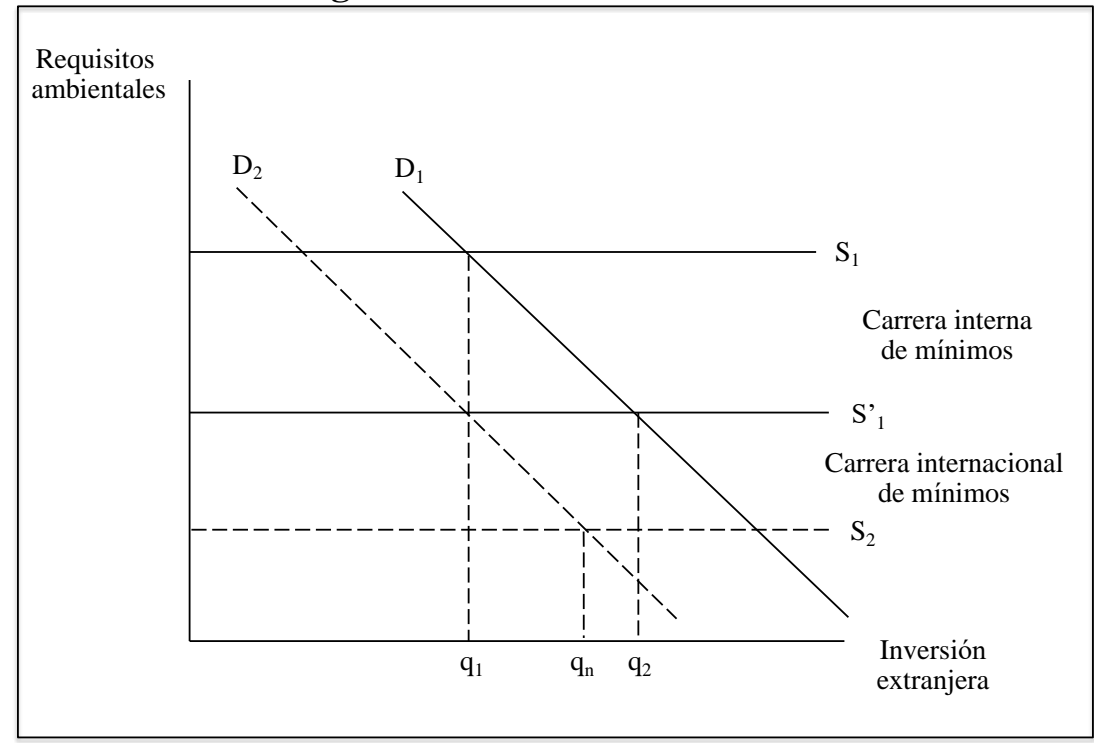

Fuente: elaboración propia.

En la Figura 1 se modeliza esta estrategia gubernamental de atracción de la inversión extranjera. La regulación ambiental por parte de los gobiernos se considera a corto plazo como de oferta $S_{1}$, independientemente de los movimientos de la inversión extranjera directa. La pendiente de la curva de demanda $\mathrm{D}_{1}$ expresa las cantidades de la inversión extranjera que se atraerán en función del costo que suponen las regulaciones ambientales (sobre el supuesto de que a mayores requisitos, mayores serán costos para las empresas). Si por un factor exógeno, como la caída de los precios de las exportaciones, un gobierno necesita atraer la inversión extranjera en minería podrá reducir los requisitos ambientales de $S_{1}$ a $S_{1}$, lo que hará caer los costos de la regulación, logrando así un incremento en el volumen de dicha inversión ( $\mathrm{de}_{\mathrm{q}} \mathrm{q}_{1}$ a $\mathrm{q}_{2}$ ) que servirá para aumentar las cantidades extraídas y exportadas a fin de compensar la reducción de los ingresos. Esto inducirá a otros gobiernos a hacer lo mismo y los requisitos de la regulación caerán hasta $\mathrm{S}_{2}$ como consecuencia de la carrera hacia el fondo internacional y en vez de conseguir más inversión, el desplazamiento de la demanda de inversión hacia la izquierda como consecuencia de la competencia entre gobiernos, dará como resultado una menor inversión (tal que $\mathrm{q}_{\mathrm{n}}$ ) y mayor destrucción por efecto de la flexibilización ambiental, social y fiscal, con la perversión añadida, de que, como en el caso de Chile, se genera "la ilusión [de] que [los gobiernos extractivistas] nunca dejan de cumplir las normas" (Gudynas, 2015: 76).

Así, la carrera de mínimos sería la expresión del derrame de la inserción internacional de los países, que también influiría en el bloqueo de la integración regional autónoma en América Latina. En este último sentido, la competencia por exportar productos primarios similares y atraer inversión 
extranjera (mediante flexibilizaciones ambientales y protección especial de los derechos de las multinacionales) hace que se desate un movimiento centrífugo que desalienta las formas de coordinación productiva y comercial regional y también propicia relaciones asimétricas por las que algunos países buscan industrializarse a costa de otros (México respecto a Centroamérica, Brasil respecto a Sudamérica) de acuerdo a la tesis dependentista del subimperialismo (Gudynas, 2015). Además de estos derrames internacionales, también existen derrames institucionales basados en la perpetración de ilegalidades y el aprovechamiento de los vacíos legales (alegalidades) para perjudicar los intereses colectivos, mientras se otorgan beneficios fiscales a las empresas que entran al juego de la gran corrupción (la captura del Estado) recurriendo a las puertas giratorias y los sobornos a políticos (Gudynas, 2015; 2018b).

En cualquier caso, la estrategia de los gobiernos de todo signo para prevenir los conflictos ambientales habría sido similar: la extracción por compensación (Gudynas, 2012a; 2015; 2018a). Compensación a título genérico en el caso de los gobiernos conservadores (fomentar el crecimiento económico supuestamente generador de empleo y reductor de la pobreza), dejando que las empresas extractivas hagan el trabajo a través de programas asistencialistas y discrecionales de responsabilidad social corporativa. En el caso de los gobiernos progresistas, la compensación se realiza mediante la financiación de programas sociales y la inversión en infraestructuras y capital humano para la diversificación de la estructura productiva a cargo de las rentas extractivas disputadas a las empresas. Pero en ambos casos, las esencias de las estrategias de desarrollo no se discuten, sino que el Estado neo-extractivista, conduce al mismo resultado o derrame (ontológico en este caso) del extractivismo: la vida social y la Naturaleza se mercantilizan cada vez más, ya que el sacrificio por tolerar la destrucción de los entornos, culturas y modos de vida insustituibles se considera puede ser compensado por un justo pago en reparación. La diferencia es que en vez de delegarlo a la responsabilidad social voluntaria de las empresas, como hacen los gobiernos conservadores, la reparación se convierte en una obligación a través de un programa público, aunque sin llegar a consolidarlo como derecho, en el caso de los gobiernos progresistas (Gudynas, 2009; 2015).

Desde la corriente de la economía ecológica (que es la base teórica de la crítica al extractivismo) se ha intentado establecer en los últimos años un enlace político entre el antiextractivismo social (los conflictos ambientales en los que se centra la crítica al extractivismo) y el post-extractivismo que se trata de promover mediante un conjunto de propuestas sobre la transición al post-extractivismo. Por mucho que compartamos la idea de que la mercantilización de la vida ha conquistado hasta el sentido común, se trata todavía de reflexiones teóricas que no contienen cálculos nacionales o simulaciones para los países afectados de los efectos presupuestarios ni de los impactos en el empleo y el sector exterior derivados de la suspensión del extractivismo; y son, además, propuesta que pecan de voluntarismo al carecer de la base y el consenso social suficiente y del entorno internacional facilitador para llevarlas a cabo. En cualquier caso, desde ese enfoque de economía ecológica, los conflictos ambientales, que se expresan en lenguajes de valoración diferentes de las estrategias estatales y empresariales de compensación de daños, se consideran como un factor potencial que podría contribuir a la transición social y ecológica (Scheidel et al., 2018; Echart y Villarreal, 2018; Pérez-Rincón, Vargas-Morales y Martínez-Alier, 2019; Akbulut, et al., 2019; Rodríguez et al., 2019). El tiempo dirá si la tercera generación de la modernización ecológica es capaz de absorber estos planteamientos y reconvertir los conflictos ambientales en un incentivo para el cambio tecnológico, tal y como plantea el enfoque de "transformación de conflictos" a partir de la idea de "ver el conflicto como oportunidad de transformación”" (Rodríguez et al., 2019: 14, 30).

\section{Estrategia de desarrollo dependiente y estilo de desarrollo insostenible}

Gudynas se ha mostrado contrario en diversas ocasiones a la ampliación de la cobertura analítica del extractivismo y ha defendido el "uso acotado y específico" de su concepto en razón de que la 
ampliación del mismo "lo vuelve más popular pero también más difuso, despojándolo de sus atributos descriptivos y analíticos" (Gudynas, 2017: 33-34). Pese a ello, fue Alberto Acosta, colaborador habitual de Gudynas, quien inició el despliegue conceptual del extractivismo identificándolo con un modelo de acumulación histórica, basado en una estrategia de desarrollo dependiente primario-exportadora que conduce inexorablemente a la maldición de los recursos, o maldición de la abundancia, como prefiere denominarla este autor (Schuldt y Acosta, 2006; Acosta 2009; 2011a; 2020). Acosta (2016) considera dicha maldición un hecho irrefutable a partir de una lectura sesgada de Prebisch -quien, al contrario, habló de "saber extraer" (Domínguez et al., 2019: 31) - y por el sencillo expediente de ignorar la prolífica literatura internacional que cuestiona la tesis de la maldición de los recursos (Badeeb, Lean y Clark, 2017; Amiri et al., 2019; Savoia y Sen, 2020).

Por su parte, North y Grinspun (2016) estudiaron la conexión entre el extractivismo y las estrategias de desarrollo que atravesaron la trayectoria de América Latina desde mediados del siglo XX hasta la actualidad: desde el desarrollismo de la CEPAL al neodesarrollismo de los gobiernos progresistas durante el último boom de las materias primas. Estos autores caracterizan el extractivismo por "la dependencia de las exportaciones de materias primas como motor del crecimiento económico" (North y Grinspun, 2016: 1483) y analizan la economía política interna que sustenta esa estrategia de desarrollo dependiente. El argumento es el siguiente. El neodesarrollismo de los gobiernos progresistas del siglo XXI persiguió idénticos objetivos al viejo desarrollismo de la CEPAL -la diversificación, el crecimiento del mercado doméstico, el empleo en los sectores de alta productividad, el bienestar social, la integración regional y una mayor autonomía en la esfera de las relaciones internacionales- pero en un contexto internacional de desregulación financiera y liberalización comercial, que estrechó el espacio de políticas autónomas para la transformación estructural productiva y distributiva. Mientras que esas tranformaciones estuvieron en la base de las políticas desarrollistas de los países del Sudeste Asiático y China -que sí lograron diversificar su estructura productiva- en los países de América Latina la persistencia de "la élite familiar de poder tradicional, que combinó los intereses agrarios, comerciales y financieros", en alianza con el capital extranjero, y con el refuerzo del control de los medios de comunicación, reprodujo el bloque de poder del período de la industrialización dirigida por el Estado (North y Grinspun, 2016: 1489).

En consecuencia, lo "nuevo" del neo-extractivismo fue el uso de las rentas de las actividades extractivas para financiar políticas públicas de bienestar, pero dichos gobiernos, al igual que los gobiernos desarrollistas de la década de 1960, no logaron romper con las estructuras sociales de la desigualdad de riqueza y poder. Los resultados de esa estrategia extractivista primario-exportadora, en la que se incluyen los sectores de la minería, los hidrocarburos y los agronegocios, fueron positivos en términos de bienestar, salud y educación, pero el neodesarrollismo progresista se olvidó del desarrollo rural igualitario que fue la base del milagro asiático. Al final, esas políticas, como las del extractivismo conservador, provocaron "nuevas oleadas de desposesión y concentración de la propiedad de la tierra en algunos países" (que alimentaron la insuficiencia dinámica de los sectores urbanos), "junto con la degradación ambiental y la criminalización de las protesta social” (North y Grinspun, 2016: 1485).

Los críticos del extractivismo (en particular Gudynas, Acosta, Svampa y Lander) han centrado casi exclusivamente su análisis en los gobiernos progresistas a los que acusan de haber dado la vuelta a las tesis de las teorías estructuralistas y marxistas de la dependencia y de coincidir con los conservadores en la criminalización de las movilizaciones y protestas. Concentrados en convertir el extractivismo en un mecanismo de crecimiento con redistribución a través de un nuevo papel más activo del Estado (Estado compensador), los gobiernos progresistas olvidaron las viejas críticas a las economías de enclave y el deterioro estructural de los términos de intercambio gracias al boom de los precios de las materias primas por la demanda china (Gudynas, 2009; 2010b; 2011b; 2015; 2018c; Machado, 2015). Así, los gobiernos progresistas o posneoliberales coincidieron con los gobiernos neoliberalesconservadores en un Consenso de los Commodities (Svampa, 2012; 2013). Sucesor del Consenso de Washington, este nuevo sentido común consistió en un "acuerdo -tácito, aunque, con el paso de los 
años, cada vez más explícito- acerca del carácter irrevocable o irresistible de la actual dinámica extractivista", y como tal fue "más allá de las diferencias entre los regímenes políticos existentes" en su papel de mantener a América Latina en "el rol de exportador de naturaleza" (Svampa, 2013: 35, 37)2.

Esa visión de un acuerdo tácito en torno a la exportación de commodities como propulsora del crecimiento ha sido criticada, no obstante, por Gudynas en razón de que los gobiernos progresistas, a diferencia de los gobiernos conservadores, tenían discursos industrialistas (sobre el cambio de la matriz productiva y la diversificación de la estructura económica). Para Gudynas, lo que existe en realidad "es una «coincidencia» en sus prácticas de desarrollo", puesto que todos los gobiernos siguen "estilos muy dependientes de las exportaciones de materias primas" (Gudynas, 2015: 376).

Al margen de esos matices (acuerdo o coincidencia), los críticos del extractivismo acusan a los gobiernos progresistas de estar dominados por el "imperativo extractivo" (Arsel, Hogenboom y Pellegrini, 2016). Este imperativo sería una ideología montada a partir de tres supuestos, sobre los que el extractivismo reconfiguró toda la acción estatal con la bendición de la CEPAL. Dichos supuestos permiten distinguir el estilo neo-extractivista progresista (de base neodesarrollista) del estilo extractivista conservador (de base neoliberal): "que la extracción intensificada es indispensable para avanzar a través de un proceso (implícitamente rostowiano) de transformación económica estructural"; "que tal transición desde las exportaciones de productos primarios hacia los bienes y servicios... de mayor valor agregado (y supuestamente más sostenibles) debe ser orquestada y, en gran medida, ejecutada por el Estado"; "y que la pobreza y la desigualdad deben abordarse urgentemente a lo largo de esta transición y no dejarlas de lado como objetivo final del desarrollo" (Arsel, Hogenboom y Pellegrini, 2016: 881).

Mientras que para el extractivismo conservador el desarrollo se reduce simplemente al crecimiento económico a partir de las ventajas comparativas, para el neo-extractivismo esa estrategia solo genera un crecimiento dependiente (consumidor de recursos naturales con insuficiencia dinámica en la creación de empleo), por lo que el desarrollo debe ser un proceso de cambio estructural inducido por la acción del Estado con políticas industriales. Mientras que para el extractivismo conservador el crecimiento genera reducción de pobreza por efecto derrame (sin importar la desigualdad), para el neoxtractivismo la reducción de la pobreza y la desigualdad deben acompañar al crecimiento económico (Domínguez y Caria, 2016). De ahí que para calificar el estilo de desarrollo de los gobiernos progresistas, algunos autores hablen de socialdesarrollismo (Katz, 2015). El neo-extractivismo sería entonces una estrategia de crecimiento impulsada no solo por las exportaciones, sino principalmente por la mejora de la capacidad adquisitiva de los salarios y el incremento de la propensión media al consumo por efecto de la redistribución del ingreso, en un modelo de capitalismo regulado donde el Estado recupera un papel central en la gestión del crecimiento (Domínguez y Caria, 2016).

El socialdesarrollismo tendría dos variantes asociadas a diferentes bases de exportación de recursos naturales (Córdoba et al., 2018). La de los países que intentaron una transformación social por medios constitucionales a partir de la creación un nuevo régimen (socialismo ecológico en Venezuela, Vivir Bien en Bolivia y Buen Vivir en el Ecuador), cuya base de exportación fueron los hidrocarburos. Y la de los países que intentaron una transformación social por medio de estrategias y políticas neodesarrollistas (Brasil, Argentina y Uruguay), cuya base de exportación fueron los cultivos flexibles (soja y biocombustibles). Por tanto, el neo-extractivismo sería parte de la ideología del desarrollo y serviría para justificar un "capitalismo benévolo" que utiliza los excedentes de las actividades extractivistas captados por el Estado para programas sociales (Gudynas, 2010b). Esto permitiría presentar los impactos sociales y ambientales ocasionados por tales actividades como un sacrificio transitorio -la "vieja concepción colonial, sacrificial-desarrollista de los territorios" (Machado, 2015: 146) - para poder reducir la pobreza y la desigualdad. Sin embargo, al basarse en la sobreexplotación de los recursos naturales, el neo-extractivismo progresista (que también va acompañado de una expansión de los estilos de consumo occidentales con la ampliación de una clase media que aspira al modo de vida

${ }^{2}$ Machado (2015: 145) usa en el mismo sentido el término Consenso de Beijing. 
imperial) mina sus propios fundamentos: es un estilo de desarrollo insostenible (Burchardt, 2014; Burchardt y Dietz, 2014; Gudynas, 2015; Acosta y Brand, 2018; Svampa, 2013; 2019; Machado, 2013; 2015).

A pesar de que los gobiernos progresistas y los críticos del extractivismo aspiran a lo mismo (una transición al post-extractivismo) estos últimos han sido implacables con esos gobiernos y sus intentos de realineamiento internacional. Los gobiernos progresistas constituyeron (y siguen siendo después de desaparecidos) la obsesión de algunos autores, que parecen olvidar la advertencia sobre la "profundización del modelo extractivista" con la llegada de la restauración neoliberal-conservadora (Peters, 2016: 46)3 . El doble rasero aplicado por los críticos del neo-extractivismo a la "izquierda marrón" (Gudynas, 2012b) se reproduce en el plano internacional y geopolítico: a pesar de que EEUU y Canadá son socios principales del comercio internacional y las inversiones de las industrias extractivas de América Latina, a China se le atribuye en exclusiva "la profundización de un extractivismo neodependentista" en la región (Svampa, 2019: 95), e incluso la condición de potencia "imperialista que reproduce las relaciones clásicas entre centro y periferia de los viejos imperios" (Lander, 2019: 131). En resumen, la posición teórica de los críticos del neo-extractivismo se basa en denunciar las incoherencias ideológicas de los gobiernos progresistas, pero el aroma maximalista en ocasiones deslegitima unas críticas que "olvidan el hecho de que el movimiento de las naciones históricamente desiguales hacia la inclusión social no se puede hacer en unos pocos años" (Córdoba et al., 2018: 68).

En este sentido, no todos los extractivismos son iguales, ni siquiera en la aplicación concreta del "nuevo régimen de asignación asimétrica de derechos" (Machado, 2013: 141; cursivas en el original) entre los inversores internacionales y las comunidades especialmente indígenas. Faundez (2017) cifra la preferencia dada a los derechos de los inversores sobre los de las comunidades en la diferente naturaleza jurídica de tales derechos: mercantil y de derecho internacional privado, en el caso de los derechos de los inversores, concretados en los acuerdos bilaterales y multilaterales de inversión asociados a los tratados de libre comercio de la doctrina del Consenso de Washington/Davos (Petras y Veltmeyer, 2014); y de derecho internacional público, y, por tanto, soft law, en el caso de los derechos colectivos, asentados en el Convenio 169 de la OIT sobre Pueblos Indígenas y Tribales en Países Independientes de 1989 en vigencia desde 1991, el Principio 21 de la Declaración de Río de 1992, el Convenio sobre Biodiversidad Biológica en vigor desde 1993, y la Declaración sobre los Derechos de los Pueblos Indígenas de las Naciones Unidas aprobada en 2007 (Faundez, 2017; Gibson y Bradshaw, 2018). Sin embargo, el jurista también atribuye la responsabilidad a los propios gobiernos, que no fueron "espectadores inocentes", sino que trataron de "aprovechar deliberadamente las contradicciones dentro del marco regulatorio internacional para perseguir su objetivo a corto plazo de aumentar los ingresos por exportación" (Faundez, 2017: 136). Es más, los gobiernos fallaron al implementar su propias leyes de protección de los derechos de la naturaleza y las comunidades por falta de voluntad política, sabotearon las decisiones de sus cortes de justicia e ignoraron las recomendaciones de las agencias internacionales cuando contradijeron sus decisiones políticas, así que también en este punto la ideología de la buena gobernanza fracasó (Faundez, 2017).

Estilizando el argumento, se podría decir que los gobiernos de diferente signo, ante la tesitura de responder a sus obligaciones para con los inversores, por un lado, y las comunidades y el medio ambiente, por el otro, tomaron la vía extractivista ${ }^{4}$. Ahora bien, al contrario de lo que afirma la crítica

3 El aporte de Svampa y Teran (2019) representa una necesario corrección en la valoración del neo-extractivismo, conceptualizado aquí como un modo de acumulación y territorialización propio de América Latina en los últimos años. Los autores sintetizan en tres fases la evolución del neo-extractivismo y en la última estudian conjuntamente los gobiernos progresistas y los neoliberal-conservadores, en particular, la "exacerbación del neoextractivismo" con el giro a la derecha de Argentina y Brasil, "cuyos gobiernos profundizaron el modelo extractivista en todas sus versiones, acentuaron la violencia estatal sobre las poblaciones más vulnerables y aplicaron una serie de políticas públicas que conllevan una significativa regresión en términos de derechos sociales" (Svampa y Teran, 2019: 183, 196-197).

${ }_{4}^{4}$ Veltmeyer (2013: 8) resume esa posición hablando de "la coincidencia de intereses económicos entre las empresas y los gobiernos en un régimen de extracción de recursos: ganancias para los primeros, y de los recursos para estos últimos". 
del extractivismo a partir de la identificación de un núcleo central de ideas (neo)desarrollistas que trasciende las diferencias sobre el papel del Estado, el uso de las rentas y sus legitimaciones políticas sí hubo sensibilidades diferentes en el tratamiento de los conflictos entre las transnacionales y los movimientos de resistencia local (López y Vértiz, 2015). Como se aprecia en la Figura 2, los gobiernos neo-extractivistas de Ecuador y Bolivia sacrificaron los derechos de los indígenas y de la naturaleza en una proporción menor (la que marca la línea de trade off entre los derechos de los inversores privados $\mathrm{D}_{\mathrm{p}} \mathrm{y}$ los derechos colectivos de las comunidades $\mathrm{D}_{\mathrm{c}}$ ) de lo que lo hicieron los extractivismos clásicos o conservadores de Colombia, Perú y Chile (de ahí la mayor pendiente de la línea de trade off de derechos $\mathrm{D}_{\mathrm{p}}^{\prime}-\mathrm{D}_{\mathrm{c}}{ }_{\mathrm{c}}$. En efecto, lo que los primeros otorgaron a los inversores privados en protección de derechos $^{5}$, el área $0 \mathrm{NQ}$, debería haber sido equivalente a lo que sacrificaron en términos de derechos colectivos, el área OQD c, pero probablemente correspondió al área PNQD'c. Pero aunque hubo pérdida neta de derechos resultó menor (por compensación) que en el caso de los gobiernos conservadores. Lo que Colombia, Perú y Chile otorgaron a los inversores en protección de derechos, el área $\mathrm{D}_{\mathrm{p}} \mathrm{C}$, fue desde el principio mayor de lo que pretendían sacrificar en términos de derechos de colectivos, el área $\mathrm{CN} 0$, pero en la práctica lo que se sacrificó fue mucho mayor y también mucho mayor que en el caso del neo-extractivismo progresista, el área $\mathrm{CND}_{c} 0$, y las compensaciones resultaron menores en coherencia con la menor recaudación de rentas.

Figura 2. El trade off entre los derechos de los inversores privados y los derechos colectivos

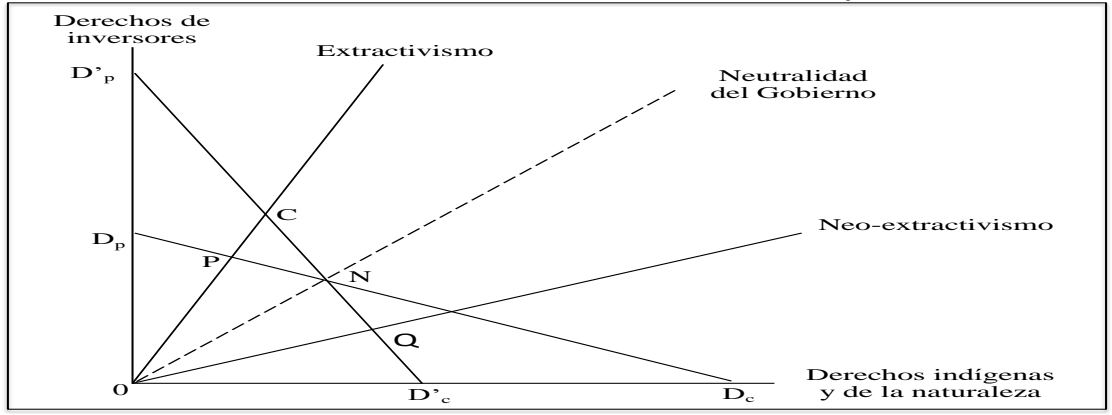

Fuente: elaboración propia.

Que los gobiernos dieran prioridad a los derechos de los inversores sobre los derechos colectivos no significa que lo hicieran para maximizar las rentas extractivas como supone Faundez (2017). En realidad, ese objetivo está sujeto a restricciones de economía política internacional y nacional que a corto plazo resultan inescapables. América Latina no pudo aprovechar el último súper-ciclo de los precios de la minería y los hidrocarburos "por la incapacidad del Estado de apropiarse de los excedentes generados por el auge", mientras que, las compañías extractivas "se apropiaron de la mayor parte de aquellos excedentes" (Ahumada, 2019: 68). Por tanto, este último ciclo reforzó la dinámica de las economías periféricas, y la trampa de especialización en recursos naturales (la reprimarización) consolidó la desindustrialización prematura y el estancamiento de los últimos años (Ahumada, 2019). A partir de la crisis financiera del Atlántico Norte y del fin del auge de las materias primas se agudizaron los problemas estructurales de la restricción externa de balanza por cuenta corriente de ese modelo, de forma que el crecimiento liderado por las exportaciones dio paso al crecimiento liderado por el endeudamiento, todavía más vulnerable que el anterior (Abeles y Valdecantos, 2017). Si no se tiene en

\footnotetext{
${ }^{5}$ Recuérdese que Bolivia y Ecuador no firmaron tratados de libre comercio con Estados Unidos, rechazaron los tratados bilaterales de inversión, se retiraron del Centro Internacional de Arreglo de Diferencias relativas a Inversiones Extranjeras (CIADI) en 2007 (Bolivia) y 2009 (Ecuador), que Ecuador promovió la creación de instancias regionales para sustituir al CIADI en el ámbito de la UNASUR (Centro de solución de controversias en materia de inversiones), así como la Conferencia Ministerial de Estados Latinoamericanos afectados por Intereses Transnacionales y el Observatorio del Sur sobre Inversiones y Transnacionales; por último el Acuerdo de Asociación Ecuador con la Unión Europea no incluyó capítulo de inversiones, a diferencia del Tratado Multipartes con Perú y Colombia que sí lo incorporaron (Campodónico, 2016; Aponte, 2018).
} 
cuenta el contexto internacional, como ya sugirieron North y Grinspun (2016), es imposible entender los limitantes y contradicciones de neo-extractivismo y, siguiendo el enfoque dependentista, esos limitantes externos resultan decisivos. En concreto, el sesgo anti-desarrollista de la OMC y los tratados de libre comercio del modelo neoliberal de integración del regionalismo abierto desde la década de 1990 (Vernengo, 2018; Ahumada, 2019); y el aumento de las dificultades para la integración regional por el incremento de la heterogeneidad política y económica regional desde el fin del auge de las materias primas y la extrema volatilidad exterior y geoestratégica introducida por la presidencia de Trump (Estay, 2018).

En suma, la crítica al extractivismo amplió la cobertura del concepto para caracterizar un estilo de desarrollo insostenible que unifica tanto a gobiernos conservadores como a gobiernos progresistas. Esta crítica posdesarrollista se centró en la denuncia de los elevados impactos sociales y ambientales de un sector al que se le niega el carácter industrial ${ }^{6}$ y que, tras el fin del auge de los precios, amplió los márgenes intensivo (aumento de las extracciones de recursos existentes para compensar las caídas de los ingresos por exportación) y extensivo (la ampliación de la frontera extractiva y la búsqueda de nuevos sectores) gracias a la colaboración de los gobiernos. Así, en pocos años, se pasó de la "ilusión desarrollista" de la convergencia (Svampa, 2019: 29) a una carrera de mínimos basada en la flexibilización ambiental y laboral, cuando no directamente en la perpetración de ilegalidades y el aprovechamiento de los vacíos legales para perjudicar los intereses colectivos mientras se otorgan cada vez más beneficios fiscales a las empresas (Ballón et al., 2017; 2018; Gudynas, 2018a; 2018b). Todo ello devuelve a América Latina al punto de partida del problema de la competitividad espuria de Fajnzylber (1992), aquella basada en la desvalorización del trabajo y la depredación de los recursos naturales. Pero la pregunta es si el sueño neoestructuralista de la CEPAL del desarrollo endógeno es posible en el contexto actual de agotamiento del excedente ecológico. De ello se ocupa la última variante del extractivismo.

\section{Extractivismo como núcleo duro del capitalismo}

En los últimos años, la crítica al extractivismo ha ido ampliando su cobertura analítica hasta el extremo de atribuir al concepto un estatus teórico generalizado como modelo histórico de acumulación conducente, por medio del proceso de desarrollo desigual, a la dependencia del capitalismo financierizado contemporáneo. Así, el extractivismo se estaría convirtiendo en "un ingrediente central del capitalismo actual" (Ye et al., 2020: 163). El extractivismo sería la expresión del imperialismo, que "no es un estadio (ni siquiera el último)" sino una característica "inherente a la expansión del capitalismo" como empresa de devastación a nivel mundial y cuyos objetivos serían "el control de la expansión de los mercados, el saqueo de los recursos naturales de la tierra, [y] la súper-explotación de las reservas de trabajo en la periferia", como sentenció Samir Amin (2000).

\subsection{Acumulación permanente, capitalismo extractivo y modo de vida imperial}

Es Amin a quien originalmente se debe la idea de que los mecanismos de la acumulación primitiva "no solo se encuentran en la prehistoria del capitalismo: también son contemporáneos": se trataría de "formas renovadas pero persistentes de acumulación primitiva en beneficio del centro" en un esquema de dominación que funciona "a escala global" (Amin, 1970: 14). Este carácter permanente de la acumulación y su lógica de privatización o "cercamiento" es la que llevó a Massimo De Angelis a

\footnotetext{
6 "hablar de «industrias extractivas» es un error conceptual. Si bien el término es muy frecuente, bajo la definición aquí presentada, el extractivismo no es una «industria». La simple extracción de un recurso no configura una industria, ya que lo que se exportan son materias primas, sin pasar por los procesamientos que son propios de la manufacturación" (Gudynas, 2015: 20).
} 
hablar más tarde de "acumulación primitiva inherente y continua", en la que categoría central sería la "separación" de los productores de sus medios de producción (De Angelis, 2004: 60, 63). Para De Angelis, los cercamientos (enclosures) constituyen un "elemento continuo de la acumulación de capital" y en su proceso de identificación por parte del capital es clave el concepto de "límite como frontera... el borde que divide lo colonizado de lo colonizable" (De Angelis, 2004: 72; cursivas en el original). Esta identificación de la frontera por el capital (como relación social de producción) implica "la creación de un espacio de cercamientos, un horizonte dentro del cual las políticas y las prácticas promueven una mayor separación entre las personas y los medios de producción en las nuevas esferas de la vida" y que afecta a la tierra y los recursos naturales, los espacios urbanos, los servicios públicos y el conocimiento (De Angelis, 2004: 73). Al mismo tiempo, David Harvey relacionó el imperialismo con un proceso de "acumulación basada en la depredación, el fraude y la violencia", de carácter "permanente" (Harvey, 2003: 144) y "omnipresente, sin importar la etapa histórica" (Harvey, 2004: 115), que, por lo mismo, calificó como "acumulación por desposesión". Con la crisis orgánica de sobreacumulación actual (por la tendencia al estancamiento secular), algunos autores hablan incluso de "acumulación militarizada o acumulación por represión" (Robinson, 2019: 161). El elemento común de estas cuatro interpretaciones, que es el acceso a los recursos naturales para su mercantilización, corrobora la afirmación de que el extractivismo se habría convertido en "la principal característica del capitalismo global" (Ye et al., 2020: 163).

Esa trayectoria histórica se explica por la tendencia del extractivismo a la intensificación, la extensificación y la diversificación (de actividades, estrategias y lógica económicas). Así, las denominadas industrias extractivas, que impulsan procesos de desposesión de los comunes (tierra, agua y energía) por medio de la violencia, pero también la persuasión (con esquemas compensación), la seducción (mediante la retórica del valor compartido de la responsabilidad social empresarial) y la manipulación (la participación selectiva externalizada a ONG previamente domesticadas) (Frederiksen y Himley, 2020), han transferido sus lógicas hacia la industria agroalimentaria, los servicios desregulados (AirBnB, Uber, Amazon), y la minería de datos (Google o Facebook), que ha dado lugar a la cuarta mercancía ficticia (la experiencia humana), en la estela de la trilogía de Polanyi sobre la naturaleza, el trabajo y el dinero (Álvarez Cantalapiedra, 2018/19; Ye et al., 2020). Hasta la propia conservación ambiental se ha convertido en una nueva frontera de la financierización de la naturaleza (Sullivan, 2013).

La lógica económica del extractivismo como núcleo central del capitalismo se basa en la explotación de los recursos provistos por la naturaleza (tierra, agua, biodiversidad y recursos naturales de los comunes globales como nueva frontera) y las generaciones previas y presentes sin reproducirlos y hasta agotarlos, moviéndose después hacia nuevos dominios y localizaciones para continuar su captura extractiva del valor (Ye et al., 2020). Este "capitalismo extractivo" (Petras y Veltmeyer, 2016: 72) se caracteriza porque no produce riqueza (valor), simplemente extrae valor capturando, explotando y agotando los recursos naturales y humanos y la riqueza producida por otros (incluidos sus datos personales) para reducir los costes o el abaratamiento del trabajo, el capital, la tierra y la naturaleza (Ye et al., 2020).

Esto no es ninguna novedad puesto que, como había planteado Marx, cuanto más difícil se volviera la intensificación de la explotación del trabajo y la realización de la plusvalía en el mercado (y, por tanto, la tasa de beneficios se tornara descendente, que es lo que ocurre con el estancamiento secular actual), más importante sería la "extensión geográfica" del capitalismo (Harvey, 1975: 11). Para Harvey, el capitalismo sobrevive a través de la "producción del espacio" o más bien, mediante una serie de "ajustes espacio-temporales" que tratan de superar la tendencia hacia la sobreacumulación inherente a la lógica de ese modo de producción mediante la expansión geográfica y la reorganización espacial gracias a la inversión en infraestructuras (Harvey, 2004: 99-100), lo que Marx denominó "la aniquilación del espacio mediante el tiempo" (cfr. Harvey, 1975: 11), donde el sistema de crédito desempeña un papel fundamental. 
Así, la teoría de la acumulación basada en la expansión de la escala geográfica remite directamente a la financierización del capitalismo contemporáneo, entendido como "el incremento del papel de los motivos financieros, de los mercados financieros, de los actores financieros y de las instituciones financieras en la operación de las economías doméstica e internacional" (Epstein, 2005: 3). Y es aquí donde cabe recordar la distinción que hace Mariana Mazzucato (2019) entre creación de valor y extracción de valor. La creación de valor es un proceso colectivo asociado a las innovaciones de la economía real. La extracción de valor, sin embargo, es el producto del capitalismo rentista de la financierización de la economía: "de las actividades extractivas del sector financiero" (Mazzucato, 2019: 78).

Este capitalismo financierizado está sujeto a la lógica cortoplacista del descuento futuro que tiende a agotar los recursos naturales, como ya vieron James O'Connor (1991), Samir Amin (1992) y John B. Foster $(1992)^{7}$, y a periódicas destrucciones de valor provocadas por guerras y crisis financieras (Harvey, 2003; 2004). Se trata, por tanto, de un capitalismo extractivo que se mueve alrededor de la especulación con los recursos y los productos producidos, aprovechando una posición de dominio (monopolio) o una regulación abusiva del derecho de propiedad intelectual. Con ello se sustituye la lógica de la integración del pacto keynesiano del capitalismo fordista por la combinación de la expulsión (que afecta a personas, empresas y lugares) y la destrucción de comunidades y porciones de la biosfera. Estos dos últimos elementos incluyen los impactos de la megaminería, los cultivos de exportación, la expansión de la urbanización (vinculada al turismo, al ocio de la segunda residencia o la gentrificación) y los servicios supuestamente "colaborativos" (Álvarez Cantalapiedra y Herrero, 2015; Álvarez Cantalapiedra, 2018/19).

Sin embargo, no se debe olvidar, que, más allá de las diferencias entre el capitalismo basado en la lógica de la integración y el que se origina a partir de la gran involución de la década de 1980 con su lógica de expulsión y destrucción, ambos forman parte de la misma gran aceleración (un crecimiento exponencial que ha conducido a la extralimitación actual del sistema respecto a su base natural). Tampoco se debe idealizar la lógica de la integración, puesto que esta se basó en que los países desarrollados pudieron eludir en gran medida sus tensiones distributivas internas trasladando las contradicciones y los conflictos a los países en desarrollo, a los que se atribuyó el papel de suministradores de fuerza de trabajo y recursos naturales (Álvarez Cantalapiedra, 2018). Ello permitió al creación de un "modo de vida imperial", término que se refiere a "patrones dominantes de producción, distribución y consumo, a imaginarios culturales y subjetividades fuertemente arraigados en las prácticas cotidianas de las mayorías en los países del Norte, pero también -y crecientemente- de las clases altas y medias en los países emergentes del Sur" (Brand y Wissen, 2013: 446-447). Se trataría de un "modo de vida hegemónico" que está "ampliamente aceptado, amarrado institucionalmente y profundamente arraigado en las prácticas cotidianas de la gente", y por el cual se espera que los bienes sean "cada vez más baratos, sin importar las condiciones sociales y ecológicas en las que se producen", tanto si se refieren a energías fósiles como a metales necesarios para la economía digital (Brand y Wissen, 2013: 449).

A partir de este marco interpretativo, enraizado en la teoría de la regulación, se ha planteado una reintepretación del neo-extractivismo como un "modo" o "modelo de desarrollo" que correspondería a una fase específica del capitalismo (la que inició en la década de 1970), "donde la naturaleza y su valoración en el mercado mundial desempeña un papel decisivo para la realización del valor de cambio, y que exhibe elementos comunes a través de diferentes regímenes políticos" (Brand, Dietz y Lang, 2016: 131, 134). En América Latina, este neo-extractivismo sería "la expresión central de la dominación política" basada en el modo de vida imperial por el que se naturaliza el acceso barato a mercancías

\footnotetext{
${ }^{7}$ En particular, este último reformuló la segunda contradicción de James O’Connor como “una tendencia a la acumulación de riqueza por un lado y por otro al agotamiento de recursos, contaminación, destrucción de especies y hábitats, congestión urbana, y deterioro sociológico del ambiente vital” (Foster, 1992: 78-79).
} 
producidas de forma insostenible y a los ejércitos de la reserva de fuerza de trabajo (Brand, Dietz y Lang, 2016: 150). Como señalan Acosta y Brand (2018: 20-21), "la sangre que fluye en las venas de los modos de producción y de vida imperiales en el Norte global proviene, ni más ni menos, de las lógicas extractivistas aplicadas en el Sur global, originadas hace cientos de años. Dichos modos de producción y de vida imperiales están presentes entre las élites dominantes del Sur".

\subsection{Ecología-mundo, trama de la vida y devastación extractivista en América Latina}

El modo de vida imperial, “consumista y depredador” (Acosta y Brand, 2018: 75), es el eslabón perdido que permite conectar la tradición dependentista de la crítica al extractivismo con la tradición del modo histórico de acumulación. Y en este punto la literatura sobre el extractivismo apenas ha empezado a explorar la teoría de la ecología-mundo capitalista del historiador ambiental y geógrafo norteamericano Jason W. Moore, discípulo de Giovanni Arrighi y muy influenciado por los planteamientos del marxismo ecológico y la escuela del sistema-mundo de Fernand Braudel e Immanuel Wallerstein (Moore, 2003a; 2003b) ${ }^{8}$. De hecho, la diferenciación entre creación y extracción de valor que establece Mazzucato (2019), y que está en la base ontológica de la concepción ampliada del concepto de extractivismo, resulta escasamente original, empezando por el propio título de su obra (The $V$ alue of Everything) que ya fue propuesto antes por Moore (2014a).

La teoría de la ecología-mundo capitalista de Moore permite abordar el extractivismo como ingrediente central del capitalismo en términos de proyecto y de proceso histórico e internacional de acumulación sin fin, que entra en contradicción con las fuentes de la riqueza (la tierra y el trabajo) y lleva a su degradación y/o agotamiento, en una variación de la segunda contradicción de James O'Connor (1991), que Foster (1992) reformuló como la "ley general absoluta de la degradación ambiental en el capitalismo". Para Moore, la ecología-mundo es una teoría y sobre todo una perspectiva y un método para abordar la "forma del antagonismo del mundo moderno entre el impulso del capitalismo de acumular sin cesar y las demandas de sostenibilidad ecológica" (Moore, 2003a: 447). Ello permite analizar el capitalismo como "una civilización diferenciada y unificada a través de la cual la acumulación de capital, la producción de la naturaleza, y la búsqueda del poder forman una totalidad histórico-mundial", "una unidad dialéctica" (Moore, 2013a: 12, 16). El "principio organizador" de dicha civilización es la ley del valor, que reside en "la apropiación de las naturalezas baratas humana y extrahumana" (Moore, 2014a: 249) o sencillamente "Naturaleza Barata", en el sentido que la apropiación de la naturaleza extra-humana para producir alimentos, energía y materias primas permite la separación de los productores de sus medios de producción y crea también la fuerza de trabajo que con la naturaleza extra-humana forma los "Cuatro Baratos" (Moore, 2014a: 250)9. Como señala Moore (2015a: 35), "la explotación de la fuerza de trabajo y la apropiación de la naturaleza están entretejidas en el impulso del sistema hacia la mercantilización sin fin".

Moore (2003a; 2003b) propone, en definitiva, una relectura de la teoría del valor de Marx como teoría de la explotación de la naturaleza (extra-humana) a través de la explotación del trabajo (naturaleza humana) por medio del capital como relación social de producción: la ley del valor, como ley de la Naturaleza Barata, consiste, así, en "la búsqueda continua, radicalmente expansiva e implacablemente innovadora para convertir el trabajo/energía de la biosfera en capital (valor en movimiento)" (Moore, 2015a: 24). Para Moore, el valor está determinado por la productividad del trabajo (tasa de explotación) en la producción de mercancías a partir de la producción/mercantilización de la naturaleza mediante técnicas aportadas por las revoluciones cartográfica, científica y estadística: una estrategia civilizatoria "para construir la naturaleza como algo externo de la actividad humana y así movilizar el trabajo no

\footnotetext{
${ }^{8}$ La prolífica obra de Moore apenas ha empezado a referenciarse en la tradición dependentista de la crítica del extractivismo, Véase Cuevas, del Valle y Véjar (2016), Teran (2016) y Svampa y Teran (2019).

${ }^{9}$ Más adelante, Moore refinará este esquema a partir de siete elementos baratos: "naturaleza, dinero, trabajo, cuidado, alimentos, energía y vidas" (Patel y Moore, 2017: 16).
} 
mercantilizado de la naturaleza, humana y extra-humana" (Moore, 2014b: 144). Ello implica superar -y aquí reside la novedad metodológica de la ecología-mundo- la trampa del dualismo cartesiano que divide la realidad en Sociedad y Naturaleza y, por ende, la falsa dicotomía ética entre antropocentrismo y biocentrismo: volviendo a Marx, los humanos son parte de la naturaleza o trama de la vida ${ }^{10}$. De lo que se trata es de analizar la relación sociedad-naturaleza en una perspectiva histórica y dialéctica desde el concepto web of life, donde los seres humanos y la Naturaleza no están disociados, sino que hacen parte del mismo sistema (Moore, 2003b; 2013a; 2013b; 2014a; 2014b; 2015a; 2015b; 2016; 2017a; 2017b; 2017c; 2018). Por tanto, el capitalismo es una "forma de organizar la naturaleza" concebida como "trama de la vida: como un todo que incluye a los humanos" y que el autor denomina oikeios (Moore, 2015a: 14, 15, 17) La trama de la vida resume la teoría unificada del capitalismo (Capitaloceno) como ecología-mundo, que integra por definición la perspectiva de género en un esquema global, político-económico y ecológico: sin el trabajo gratuito de "las mujeres, la naturaleza y las colonias... la acumulación flaquea" (Moore, 2015a: 238). En su "teología de la sustitución sin fin" para elevar la productividad del trabajo (Moore, 2014a: 263), "la acumulación del capital es la transformación de la naturaleza" por medio del trabajo; y también "es la proletarización del trabajo, es la apropiación de la naturaleza global": trabajo y naturaleza "son dos caras de la misma moneda" (Moore 2013a: 12, 14).

En América Latina se ha desarrollado de modo independiente un enfoque autóctono que comparte con el pensamiento de Moore el marco del marxismo ecológico y la idea de acumulación por desposesión/apropiación dentro del sistema-mundo como una característica inmanente del desarrollo dependiente latinoamericano. Desde la Conquista, "el mayor despojo y genocidio de la historia", hasta nuestros días se podría trazar un línea de continuidad entre el "extractivismo histórico" y el neoextractivismo (Galafassi y Composto, 2013: 79, 83) ${ }^{11}$. En esta original revisión conceptual destacan los trabajos de Guido Galafassi (2012) y Horacio Machado (2013; 2015).

El primero, a partir de una revisión a profundidad del concepto de acumulación primitiva y originaria de Marx, habla de la "ecuación apropiatoria", esto es, "la acumulación [permanente] basada en la predación y la violencia sin disimulo" como una de las claves que han convertido a América Latina en "oferente de espacios y territorios rurales para la extracción de hidrocarburos, minerales, biodiversidad, y alimentos bajo la fórmula clásica de la división internacional del trabajo" (Galafassi, 2012: 3). Galafassi propone también el concepto de "alienación socio-ecológica" para describir el "proceso de cercamiento" por el que se logra la "separación de las poblaciones respecto de sus medios históricos de producción": frente a los viejos cercamientos que fueron el soporte inicial de la nueva legalidad y legitimación del capitalismo, los cercamientos "actuales se construyen a partir de una legalidad ya constituida" (Galafassi, 2012: 6-8). Finalmente, para el antropólogo argentino, el neoextractivismo se debería entender como un "modelo de desarrollo" característico de las dinámicas de América Latina desde inicios del siglo XXI bajo el cual deberían agruparse todos los gobiernos de la región, independientemente de su orientación progresista o neoliberal-conservadora (Galafassi y Composto, 2013: 82).

Por su parte, Machado considera que "el extractivismo surge de y con la conquista y colonización de «América» y se va consolidando y transformando, luego, correlativamente a la mundialización del capital", de modo que el extractivismo estaría "en las propias raíces geo-económicas y geopolíticas del capitalismo como economía-mundo", daría cuenta de la "división imperial-colonial de la producción y el consumo a escala mundial" y sería, por tanto, "indisociable del capitalismo" (Machado, 2013: 131). El extractivismo no constituiría una etapa o fase, sino "un rasgo estructural del capitalismo como economía-mundo", o siguiendo la interpretación ecologista de Marx, "una dimensión fundacional y constitutiva del sociometabolistmo del capital” (Machado, 2013: 131-132; cursivas en el original). Machado llega

${ }^{10}$ Esta dicotomía hace parte del repertorio de la crítica al neo-extractivismo de Gudynas (2003; 2010a; 2010c; 2011c; 2015; 2018c), Acosta (2009; 2011b; 2015; 2016), Svampa (2019) y Lander (2019).

11 En este mismo sentido es en el que utilizan el término neo-extractivismo Brand, Dietz y Lang (2016), Merchand (2016), Puyana (2017), Svampa y Teran (201) y Corrado (2020). 
a la misma conclusión que Moore: el cuerpo humano es parte de la naturaleza, así que distinguir entre exterioridad e interioridad solo tiene sentido "para aludir a dos momentos o instancias de realización de la misma materia viviente", mientras que la ruptura metabólica alude a los "procesos históricos de expropiación... como actos de violencia radical" a través de los cuales "unos determinados cuerpospoblaciones" son separados "de sus respectivos territorios-medios de vida" (Machado, 2013: 132-133). Así, "al apropiarse de los medios de vida (Tierra-territorios) y al operar correlativamente la mercantilización de las energías corporales (trabajo) para desviarlas hacia la producción de mercancías y la acumulación de valor abstracto", el capital altera radicalmente los sistemas bioeconómicos (la producción de valores de uso para la reproducción de la vida) "para subsumirlos en la dinámica necroeconómica de la acumulación sin-fin y como fin-en-si-mismo" de los valores de cambio (Machado, 2013: 133-134; cursivas en el original).

El cientista social argentino propone además un aparato conceptual emergente (alienación territorial, plusvalía ecológica y expropiación ecobiopolítica) con el que se resumen para América Latina "los efectos radicales y de larga duración de los regímenes extractivistas" (Machado, 2013: 141). En tal sentido, Machado distingue entre extractivismo y regímenes extractivistas. El extractivismo sería "una dimensión estructural (ecológico-geográfica) y una función constitutiva del sociometabolismo del capital como sistema-mundo", mientras que los regímenes extractivistas se refieren a "las formaciones coloniales-periférico-dependientes de aquél" y que "dan cuenta de la modalidad específica que el capitalismo adquiere en la periferia" (Machado, 2015: 153). Dicha modalidad se basa en "la sobreexplotación exportadora de naturaleza", lo que implica "una tasa de extracción de recursos superior a la de los tiempos biológicos, químicos y geológicos de reposición natural" (Machado, 2015: 151; cursivas ene el original). Machado, además, habla del "extractivismo neoliberal" como un régimen extractivista en el que la súper-explotación del trabajo y de los recursos naturales lleva al límite la "devastación del mundo de la vida" (Machado, 2015: 143, 156).

La alienación territorial, que Machado toma prestada del geógrafo brasileño Milton Santos, alude a los fenómenos de desterritorialización-reterritorialización de las poblaciones locales y sus modos de vida como consecuencia de las "mega-inversiones extractivistas" del capital transnacional (Machado, 2013: 138). La plusvalía ecológica es "el efecto integral de apropiación y consumo desigual de naturaleza que se diseña a través de una geografía de la extracción completamente diferente a la geografía del consumo": de un lado, "la destrucción, degradación y pérdida de capacidad productiva de los ecosistemas", y, de otro, "la transferencia neta de activos ecológicos desde estos territorios-ecosistemas-poblaciones hacia las sociedades donde finalmente esos bienes son procesados y consumidos" (Machado, 2013: 139; cursivas en el original) ${ }^{12}$. Finalmente, la expropiación eco-biopolítica, que engloba los efectos de los dos primeros conceptos, se refiere a "un sistema integral de dominio, control y disposición que se ejerce sobre el complejo de la vida social en general, desde sus fuentes materiales y estratos geofísico-biológicos básicos, hasta las principales manifestaciones socio-institucionales de la vida colectiva" (Machado, 2013: 140).

\subsection{De las fronteras de las mercancías al Capitaloceno}

Los principales conceptos de la teoría de Moore, que enlazan con la ampliación de la cobertura conceptual del extractivismo, son el de frontera de las mercancías -tomado de la cadena de las mercancías de Hopkins y Wallerstein (1986) - y el de acumulación por apropiación y capitalización -y su par correspondiente de saqueo y productividad-, como ampliación de la reinterpretación que hace Harvey de Marx. El esquema, en todo caso, arranca directamente de Marx y la consideración de que el

\footnotetext{
12 La comprobación empírica del intercambio económico y ecológico desiguales se puede consultar en los trabajos de Samaniego, Vallejo y Martínez-Alier (2017) e Infante-Amate, Urrego y Tello (2020).
} 
capitalismo tiende hacia "la mercantilización de todo... a disolver las fuentes originales de la riqueza, la tierra y el trabajo, en una métrica que hace caso omiso de la diversidad de la vida" (Moore 2003a: 453).

Frontera de las mercancías. Con la conquista de América (la Gran Frontera, con 4 millones de $\mathrm{km}^{2} \mathrm{y}$ 25 millones de indígenas), el azúcar y la plata fueron centrales para el surgimiento no solo de la economía mundo (y su división centro-periferia) sino de la ecología-mundo, articulándose con otras grandes fronteras de mercantilización en torno al cobre, el hierro, los productos forestales y pequeros y la agricultura cerealera (Moore, 2003b; 2013a; 2018). La prioridad dada al incremento de la productividad del trabajo (tasa de explotación) como fuente de ganancia en el capitalismo se hizo a costa de la destrucción de la naturaleza por medio de "la expansión continua de las extensiones geográficas para la apropiación" (Moore 2013a: 13), o "frontera de las mercancías" (Moore, 2003c: 132), en un proceso de apropiación y simplificación de la naturaleza humana y extra-humana, del trabajo y de la tierra. El capitalismo, por medio de la apropiación de la naturaleza a través de la explotación del trabajo, provocó la degradación y extenuación de una región tras otra, o “sobreapropiación secuencial” (Moore, 2013a: 18), en un ciclo de expansión geográfica recurrente y de desarrollos insostenibles para eludir el descenso de la productividad del trabajo y de la tasa de ganancia (Moore, 2003b). A partir de ahí, el concepto de frontera de las mercancías se expandió no solo en el plano geográfico, sino que, dada la tendencia del capitalismo a mercantilizarlo todo, se diversificó mediante la "apropiación máxima" (Moore 2013b: 26): de todo lo que contiene la Naturaleza, incluida la vida humana, aumentando así "el ejército de fuerza de trabajo" (Moore, 2013a: 13). En suma, la frontera de las mercancías se puede entender como "un proceso de ir más allá de las zonas de producción altamente capitalizadas [los centros de la ecología-mundo] para asegurarse las fuentes de trabajo, alimento, energía y materias primas por debajo de los costes medios prevalecientes" en las periferias (Walker y Moore, 2019: 55). La conexión de este enfoque con la definición original de extractivismo es evidente, por cuanto la frontera de las mercancías presupone la apropiación de la naturaleza (humana y extra-humana) y, por ello, el círculo conceptual del extractivismo como modo de apropiación se cierra.

Acumulación por apropiación y capitalización. Las apropiaciones de frontera permitieron capturar vastas reservas de trabajo, alimentos, energía y materias primas -los cuatro grandes factores de producción contenidos en la "Naturaleza Barata" (Moore, 2014a; 2014b; 2015a; 2015b; 2016; 2017a; 2017b; 2017c; 2018; Patel y Moore, 2018; Walker y Moore, 2019)- que reducen los costos de producción. La Naturaleza Barata es, por tanto, la condición necesaria para la acumulación de capital, en la medida en que una gran parte de los costes de reproducción de los Cuatro Baratos (trabajo, alimentos, energía y materias primas) quedan sin retribuir por considerarse un regalo (en el caso de la naturaleza extra-humana) o un asunto doméstico y objeto de extracción de excedente y por tanto devaluable (en el caso de la naturaleza humana). De esa forma, la "acumulación por apropiación", es decir, el "saqueo de las zonas de frontera" en la periferia (por la cual los cuatro grandes factores de producción son apropiados con la mínima inversión de capital) permite la "acumulación por capitalización" (Moore, 2013a: 14). Esto es lo que sucede cuando esa Naturaleza Barata de la frontera o periferia, además de liberar fondos para la inversión en maquinaria, se pone a trabajar para el aumento de la productividad del trabajo en el centro (Moore, 2013a; 2013b; 2014a; 2014b).

El mensaje final de Moore es que la crisis ecológica actual no se puede entender desde la teoría malthusiana del Antropoceno, que concibe la Naturaleza como separada de los seres humanos de acuerdo a la visión del dualismo cartesiano. El Antropoceno es un "viejo truco capitalista" consistente en "decir que los problemas del mundo son los problemas creados por todos cuando en realidad han sido creados por el capital" (Moore en Muntané, 2017: 109). El Antropoceno supone que la proliferación de los seres humanos desde la Revolución Industrial es una fuerza geológica, lo que naturaliza las desigualdades, la alienación del trabajo y la violencia inscrita en las relaciones de poder y producción que iniciaron con el capitalismo histórico y su incesante búsqueda de naturaleza barata. Por el contrario, para Moore, la crisis ecológica actual es producto del Capitaloceno (una Era del Capital), 
donde la acumulación por apropiación de la Naturaleza Barata entra en contradicción con la trama de la vida conduciendo a la degradación de la naturaleza humana y la simplificación de la naturaleza extrahumana por la destrucción ambiental y la pérdida de biodiversidad (Moore, 2015a; 2015b; 2016; 2017c; 2018). La crisis ecológica actual es parte de la crisis ecológico-mundial capitalista, y su correlato de intensificación, extensificación y diversificación de las fronteras extractivas que ha conducido al agotamiento de la estrategia basada en la Naturaleza Barata, esto es, a la reducción del excedente ecológico. Ello sería fruto de cuatro procesos. En primer lugar, el funcionamiento de la ley de entropía (que aumenta el valor negativo en forma desechos, contaminación y fenómenos climáticos extremos provocados por el calentamiento global). En segundo lugar, el aumento más rápido de la tasa de acumulación de capital que la tasa de explotación del trabajo, lo que provoca el aumento de las desigualdades funcionales e internacionales en la distribución del ingreso y las consiguientes crisis de superproducción y de subconsumo. En tercer lugar, el descenso de la tasa de retorno energético del capital invertido, que dispara los costos ambientales. Y, por último, el aumento más rápido de la tasa de acumulación de capital respecto de la reproducción de la naturaleza, que conduce a rendimientos decrecientes y una carrera hacia el fondo detonadora de conflictos (Moore, 2015a; 2015b; 2016; 2017c; 2018).

Este último elemento devuelve el análisis macroeconómico y macrohistórico de Moore al planteamiento microeconómico de Gudynas contra el optimismo tecnológico actual y concreto de las industrias extractivas. Como señala este último autor: "lo que se presenta una y otra vez como avances tecnológicos de los extractivismos en realidad son peleas contra la escasez, y formas de ocultar los rendimientos decrecientes" (Gudynas, 2015: 30). Para Moore, el fin de la Naturaleza Barata no tiene por qué conducir a la pesadilla destructiva de la vida bajo el Capitaloceno, que por cierto el capitalismo verde no podrá resolver (Mahnkopf, 2019; Hickel y Kallis, 2020), sino que apela a una praxis para la transformación derivada de la teoría, el enfoque y el método de la ecología-mundo: "las estrategias populares para la liberación tendrán éxito o fracasarán a partir de nuestra capacidad para forjar una ontología diferente de la naturaleza, la humanidad y la justicia, que pregunte no solo cómo redistribuir la riqueza, sino cómo rehacer nuestro lugar en la naturaleza de una manera que prometa la emancipación para la totalidad de la vida" (Moore, 2016: 114).

\section{Consideraciones finales: hacia un Marini ecológico para la Economía de la Vida}

El despliegue del extractivismo no agota las posibilidades de análisis de un concepto que, por su genealogía marxista, se ha mostrado enormemente fértil en los últimos años. Acuñado en el ámbito del pensamiento crítico latinoamericano, el extractivismo seguirá expandiendo su cobertura analítica en el futuro. Una buena muestra de ello es la propuesta de Ramón Grosfoguel para estudiar "el «extractivismo epistémico» y el «extractivismo ontológico» como las condiciones que hacen posible el «extractivismo económico»", en razón de que los tres comparten la actitud de cosificación y destrucción producida por el capitalismo tanto en la vida humana como en la no-humana (Grosfoguel, 2016: 126).

Sin salirnos de la ontología del realismo crítico mantenida en este trabajo, la principal conclusión de nuestro análisis es que se puede realizar una integración entre las tres aproximaciones al extractivismo estudiadas a lo largo del texto para reivindicar una suerte de Ruy Mauro Marini ecológico a través del filtro de Moore y Machado, y cerrar, así, la brecha entre las dos tradiciones teóricas a partir de las cuales se ha abordado el estudio del extractivismo: la dependentista, de raíz latinoamericana, que agrupa las concepciones del extractivismo como modo de apropiación de los recursos, estrategia de desarrollo dependiente y estilo de desarrollo insostenible; y la propiamente extractivista, de dominante norteamericana y europea (con la excepción de Samir Amin y de las figuras del pensamiento propio latinoamericano como Galafassi y Machado), que remite a los procesos permanentes de acumulación por desposesión/apropiación como núcleo duro del capitalismo. De hecho, en alguno de los textos de Gudynas se habla directamente de "la sobre[e]xplotación de la mano de obra y la Naturaleza" 
(Gudynas, 2015: 33) y en el trabajo de Acosta y Brand (2018: 71) ya es posible encontrar esa integración a partir del marco de la teoría de la regulación en la que se enfatiza que el modo de vida imperial solo puede funcionar mediante la reestructuración e intensificación de "la explotación de recursos naturales globales y de la fuerza laboral".

Marini, el principal teórico marxista latinoamericano de la dependencia, consideró la súperexplotación del trabajo como el "elemento vital en la dinámica del capitalismo dependiente" (Marini, 1978: 99) y utilizó la expresión "enclave" para describir "la simple anexión de áreas de producción (por lo general extractivas, aunque también agrícolas) a los centros industrializados" (Marini 1977: 33). Por tanto, a diferencia de la lectura de Machado, se podría sostener que Marini sí tuvo en cuenta la plusvalía ecológica, esto es, la "apropiación diferencial de materia y energía" (Machado, 2015: 164). Más tarde, Fernando Fajnzylber releyó la teoría estructuralista de la dependencia a partir de la noción de competitividad espuria asentada "en recursos naturales depredados y en salarios que caen" (Fajnzylber, 1992: 12). En ese sentido, el aporte de Moore sobre la ecología-mundo y el de Machado sobre el imperialismo ecológico, que comparten con las dos versiones de la teoría de la dependencia su enfoque global, permiten reconsiderar este último intento (neo)estructuralista de la inserción activa de la periferia en la economía internacional promovido por la CEPAL como un proyecto imposible.

Como se apunta desde el marxismo ecológico, la esencia del modo de vida imperial inscrito en el Capitaloceno es, al menos desde la década de 1970, "una explotación más intensiva (una súperexplotación) del trabajo y del ambiente" (Foster, 1991: 81). Al analizar "la causa básica de la segunda contradicción", James O’Connor nos recuerda que el modo de producción capitalista se basa en "la apropiación y el uso autodestructivos... de la fuerza de trabajo, del espacio y la infraestructura urbana, y de la naturaleza o el medio ambiente externo" (O’Connor, 1991: 108). Esta última "sobreexplotación" de los recursos naturales o de la naturaleza que justamente denuncian algunos críticos del extractivismo ${ }^{13}$, es lo que permitiría la convergencia entre el llamado de Moore a superar el dualismo cartesiano -en el que todavía incurren los planteamientos de Foster y Harvey (Moore, 2014b; 2017b)- y el pensamiento crítico latinoamericano sobre la Economía de la Vida, que, como la teoría de la ecología-mundo, tiene sus raíces en la tradición del marxismo ecológico. A partir de la vuelta recuperación de Marini que ya propuso Machado se puede reinterpretar la dinámica de la acumulación capitalista a escala mundial como la extracción de un doble excedente/plusvalía: la plusvalía social basada en la "súper-explotación de los cuerpos-de-trabajadoras/trabajadores", y la plusvalía ecológica extraída a partir de la "súper-explotación de las riquezas naturales y los bienes territoriales de las economías periférico-dependientes” (Machado, 2015: 164).

Así, para cerrar el círculo del despliegue conceptual de la crítica del extractivismo es necesario conectar este Marini ecológico con la Economía de la Vida. Esta conexión convoca aa defender "la racionalidad del circuito natural de la vida humana como la última instancia de toda racionalidad" y a construir una sociedad "en la cual cada ser humano pueda asegurar su posibilidad de vida dentro de un marco que incluya la reproducción de la naturaleza, sin la cual la propia reproducción de la vida humana no es posible" (Hinkelammert y Mora, 2009: 41, 48). Tal objetivo no se podrá logar solo a base de decrecimiento: será necesario desconectar del Capitaloceno, del capitalismo, por cuanto "el capital no conoce límites cartesianos en su sed por apropiarse de la vida" (Moore, 2013a: 22) y su ley de valor provoca "la devastación del mundo de la vida" (Machado, 2015: 143).

En suma, dar paso a la Economía de la Vida, esto es, "asumir íntegramente el materialismo de Marx" (Machado, 2015: 168) podría ser el mensaje final para integrar mediante fertilización cruzada las propuestas de las dos tradiciones críticas del extractivismo a partir de la pieza que faltaba para

${ }^{13}$ Entre otros, hablan de sobreexplotación Machado (2013: 129; 2015: 151), Svampa (2013: 34; 2019: 21, 56), Burchardt (2014: 11), Burchardt y Dietz (2014: 476), Gudynas (2015: 33), Acosta y Brand (2018: 128) o Wanderley, Vera y Benavides (2019: 233). 
completar su despliegue conceptual: el marxismo ecológico y sus variantes latinoamericana y de la ecología-mundo.

\section{Bibliografía}

Abeles, M. y Valdecantos, S. (2017). South America after the Commodity Boom. En E. Pérez Caldentey y M. Vernengo (eds.), Why Latin American Nations Fail. Development Strategies in the Twenty-First Century (pp. 163-185). Oakland, University of California Press.

Acosta, A. (2009). La maldición de la abundancia. Quito: Abya-Yala.

- (2011a). Extractivismo y neoextractivismo: Dos caras de la misma maldición. En Grupo Permanente de Trabajo sobre Alternativas al Desarrollo, Mas allá del desarrollo (pp. 83-118). Quito: Fundación Rosa Luxemburg y Abya-Yala.

- (2011b). Los Derechos de la Naturaleza. Una lectura sobre el derecho a la existencia. En A. Acosta y E. Martínez (comps.), La Naturaleza con derechos. De la filosofía a la política (pp. 317-368). Quito: AbyaYala.

-(2015). El Buen Vivir como alternativa al desarrollo. Algunas reflexiones económicas y no tan económicas. Política y Sociedad, 52(2): 299-330.

-(2016). Las dependencias del extractivismo. Aporte para un debate incompleto. Aktuel Marx Intervenciones, 20: 123-154.

-(2020). Extractivism. The curse of plenty. En E. Vivares (ed.), The Routledge Handbook to Global Political Economy. Conversations and Enquires (pp. 391-407). Nueva York y Londres: Routledge.

Acosta, A. y Brand, U. (2018). Salidas del laberinto capitalista. Decrecimiento y postextractivsmo. Quito: Fundación Rosa Luxemburgo, segunda edición.

Acosta, A. y Cajas, J. (2016). Patologías de la abundancia. Una lectura desde el extractivismo (pp. 391426). En H.J. Burchardt et al. (eds.), Nada dura para siempre. Neo-extractivismo tras el boom de las materias primas (pp. 391-426). Quito: Universidad Andina Simón Bolívar y Universität Kassel.

Ahumada, J.M. (2019). The Political Economy of Peripheral Growth. Chile in the Global Economy. Cham: Palgrave Macmillan.

Akbulut, B. et al. (2019). Who promotes sustainability? Five theses on the relationships between the degrowth and the environmental justice movements. Ecological Economics, 165: 1-9.

Álvarez Cantalapiedra, S. (2018). Extractivismos, modo de vida imperial y violencia. Papeles de relaciones ecolosociales y cambio global, 143: 5-11.

- (2018/19). Capitalismo en la era digital. Papeles de relaciones ecolosociales y cambio global, 144: 5-10.

Álvarez Cantalapiedra, S. y Herrero, Y. (2015). Extractivismo y expulsiones: dinámicas organizadoras de una nueva realidad. En Fundación Foessa, Análisis y perspectivas 2015. Empleo precario y protección social (pp. 37-47). Madrid: Foessa.

Amin, S. (1970). L'accumulation a l'echelle mondiale. Tome l. París: Editons Anthropos.

- (1992). Can Environmental Problems Be Subject to Economic Calculations? World Development, 20(4): 523-530.

-(2000). Imperialism and Globalization. Monthly Review, 53(2). Recuperado de https://monthlyreview.org/2001/06/01/imperialism-and-globalization/.

Amiri, H. et al. (2019). Natural resource abundance, institutional quality and manufacturing development: Evidence from resource-rich countries. Resources Policy, 62: 550-560.

Aponte, M. (2018). Integración, geopolítica, recursos naturales y mapeo de cadenas. Un desafío metodológico para promover la soberanía frente a las empresas transnacionales. En D. Martín et al., Desafios, perspectivas y horizontes de la integración en América Latina y el Caribe: actualidad del pensamiento de Ruy Mauro Marini (pp. 257-338). Buenos Aires, CLACSO.

Arsel, M., Hogenboom, B. y Pellegrini, L. (2016). The extractive imperative in Latin America. The Extractive Industries and Society, 3(3): 380-387. 
Badeeb, R.A, Leana, H.H. y Clark, J. (2017). The evolution of the natural resource curse thesis: A critical literature survey. Resources Policy, 51: 123-134.

Balleti, B. (2014). Saving the Amazon? Sustainable soy and the new extractivism. Environment and Planing A: Economy and Space, 46(1): 5-25.

Ballón, E. et al. (2017). Minería y marcos institucionales en la región andina. El superciclo y su legado, o las difíciles relaciones entre politicas de promoción de la inversión minero-bidrocarburifera y las reformas institucionales. Reporte de investigación. Lima: Natural Resource Governance Insitute.

-(2018). La Agenda de la Sociedad Civil frente a las Industrias Extractivas en América Latina. Lima: Natural Resources Governance Institute.

Brand, U. y Wissen, M. (2013). Crisis socioecológica y modo de vida imperial. Crisis y continuidad de las relaciones sociedad-Naturaleza en el capitalismo. En En Grupo Permanente de Trabajo sobre Alternativas al Desarrollo, Alternativas al Capitalismo/Colonilismo del siglo XXI (pp. 445-470). Quito: Ediciones Abya-Yala.

Brand, U., Dietz, K. y Lang, M. (2016). Neo-Extractivism in Latin America. One Side of a New Phase of Global Capitalist Dynamics. Ciencia Politica, 11(21): 125-159.

Bunker, S.G. (1985). Underdeveloping the Amazon. Extraction, Unequal Exchange, and the Failure of the Modern State. Urbana: University of Illinois Press

Burchardt, H.J. (2014). Logros y contradicciones del extractivismo. Bases para una fundamentación empírica y analítica. Nueva Sociedad. Análisis, febrero.

Burchardt, H.J. y Dietz, K. (2014). (Neo-)extractivism - a new challenge for development theory from Latin America. Third World Quarterly, 35(3): 468-486.

Bustos-Gallardo, B. y Prieto, M. (2019). Nuevas aproximaciones teóricas a las regiones-commodity desde la ecología política. EURE, 45(135): 153-176.

Campodónico, H. (2016). Recuperar la soberanía sobre los recursos naturales: los casos de Bolivia y el Ecuador. Centro del Sur Documento de Investigación, 71.

Córdoba, D. et al. (2018). Fuelling Social Inclusion? Neo-extractivism, State-Society Relations and Biofuel Policies in Latin America's Southern Cone. Development and Change, 49(1): 63-88.

Corrado, A. (2020). Between neoliberalism and neodevelopmentalism: Socio-economic inequalities and mobilisations in Argentina and Chile. En V. Fortunato (ed.), Old and new inequalities in a globalised world. Experiences from Europe and Latin America (pp. 282-299). Turín y París: L'Hartmann.

Cuevas, H., del Valle, N. y Véjar, D.J. (2016). Capitalismo enAmérica Latina. Extractivismo, Landnahme y acumulación por desposesión. Pléyade, 18: 13-24.

De Angelis, M. (2004). Separating the doing and the deed: Capital and the continuous character of enclosures. Historical Materialism, 12: 57-87.

Domínguez, R. et al. (2019). Recursos naturales, medio ambiente y sostenibilidad. 70 años de pensamiento de la CEPAL. Santiago de Chile: CEPAL.

Domínguez, R. y Caria, S. (2016). Extractivismos andinos y limitantes del cambio estructural. H.J. Burchardt et al. (eds.), Nada dura para siempre. Neo-extractivismo tras el boom de las materias primas (pp. 89130). Quito: Universidad Andina Simón Bolívar y Universität Kassel.

Echart, E. y Villarreal, C. (2018). Resistencias y alternativas al desarrollo en América Latina y Caribe: luchas sociales contra el extractivismo. Relaciones Internacionales, 39: 141-163.

Epstein, G.A. (2005). Introduction: Financialization and the World Economy. En G.A. Epstein (ed.), Financialization and the World Economy (pp. 3-16). Cheltenham: Edward Elgar.

Estay, J. (2018). Past and Present of Latin American Regionalisms, in the Face of Economic Reprimarization. En E. Vivares (ed.), Regionalism, Development and the Post-Commodities Boom in South America (pp. 47-76). Cham: Palgrave MacMillan.

Fajnzylber, F. (1992). La transformación productiva con equidad y la sustentabilidad ambiental. En CEPAL/ONUDI: Industrialización y desarrollo tecnológico. Informe 12 (pp. 7-26). Santiago de Chile: Naciones Unidas. 
Faundez, J. (2017). The governance of natural resources in Latin America: The commodities consensus and the policy space conundrum. En C. Tan y J. Faundez (eds.), Natural Resources and Sustainable Development. International Economic Law Perspectives (pp. 117-141). Cheltenham: Edward Elgar.

Foster, J.B. (1992). The Absolute General Law of Environmental Degradation Under Capitalism. Capitalism, Nature, Socialism, 3(3): 77-82.

Frederiksen, T. y Himley, M. (2020). Tactics of dispossession: Access, power, and subjectivity at the extractive frontier. Transactions of the Institute of British Geographers, 45(1): 50-64.

Galafassi, G. (2012). Renovadas versiones de un proceso histórico en marcha. La predación del territorio y la naturaleza como acumulación. Theomai. Estudios Críticos sobre Sociedad y Desarrollo, 25: 114.

Galafassi, G. y Composto, C. (2013). Acumulación por despojo y nuevos cercamientos: el caso de la minería a gran escala en la Patagonia Argentina. Cuadernos del CENDES, 30(83): 75-103.

Gibson, J. y Bradshaw, B. (2018). Resource Extraction and Indigenous Community Consent. En D.C. Poff y A.C. Michalos (eds.), Encyclopedia of Business and Professional Ethics. Springer International Publushing, https://doi.org/10.1007/978-3-319-23514-1_128-2.

Grigera, J. y Álvarez, L. (2013). Extractivismo y acumulación por desposesión. Un análisis de las explicaciones sobre agronegocios, megaminería y territorio en la Argentina de la posconvertibilidad. Theomai. Estudios Criticos sobre Sociedad y Desarrollo, 27/28: 80-97.

Grosfogel, R. (2016). Del "extractivismo económico" al "extractivismo epistémico" y "extractivismo ontológico"; una forma destructiva de conocer, ser y estar en el mundo. Tabula Rasa, 24: 123-146.

Gudynas, E. (2003). Ecología, Economía y Etica del Desarrollo Sostenible. Quito: Abya-Yala.

- (2009). Diez tesis urgentes sobre el nuevo extractivismo. Contextos y demandas bajo el nuevo progresismo sudamericano actual. En J. Schuldt et al., Extractivismo, politica y sociedad (pp. 187-225). Quito: CAAP-CLAES.

-(2010a). Si eres tan progresista ¿Por qué destruyes la naturaleza? Neoextractivismo, izquierda y alternativas. Ecuador Debate, 79: 61-81.

-(2010b). La ecología política de la crisis global y los límites del capitalismo benévolo. Íconos. Revista de Ciencias Sociales, 36: 53-67.

-(2010c). Desarrollo sostenible: una guia basica de conceptos y tendencias hacia otra economía. Otra Economía, 4(6): 43-66.

-(2011a). El nuevo extractivismo progresista en América del Sur. Tesis sobre un viejo problema bajo nuevas expresiones. En A. Acosta et al., Colonialismos del siglo XXI. Negocios extractivos y defensa del territorio en América Latina (pp. 75-92). Barcelona: Icaria.

-(2011b). Debates sobre el desarrollo y sus alternativas en América Latina: Una breve guía heterodoxa. En Grupo Permanente de Trabajo sobre Alternativas al Desarrollo, Mas allá del desarrollo (pp. 21-53). Quito: Fundación Rosa Luxemburg y Abya-Yala.

-(2011c). Los derechos de la Naturaleza en serio. En A. Acosta y E. Martínez (comps.), La Naturaleza con derechos. De la filosofía a la politica (pp. 239-286). Quito: Abya-Yala.

-(2012a). Estado compensador y nuevos extractivismos: las ambivalencias del progresismo sudamericano. Nueva Sociedad, 237: 128-46.

- (2012b). Una izquierda marrón en América del Sur. Ecología Política. Cuadernos de debate internacional, 43: $9-12$

-(2013). Extracciones, extractivismos y extrahecciones. Un marco conceptual sobre la apropiación de recursos naturales. Observatorio del Desarrollo, 18, febrero.

-(2015). Extractivismos. Ecología, economía y politica de un modo de entender el desarrollo y la Naturaleza. Cochabamba: CEDIB.

-(2017). Neo-extractivismo y crisis civilizatoria. En G. Ortega (coord.), América Latina: avanzando hacia la construcción de alternativas (pp. 29-54). Asunción: BASE IS. 
-(2018a). Extractivisms. Tendencies and consequences. En R. Munck y R. Delgado Wise (eds.), Reframing Latin American Development (pp. 61-71). Nueva York: Routledge.

-(2018b). Extractivismos: el concepto, sus expresiones y sus múltiples violencias. Papeles de relaciones ecosociales y cambio global, 143: 61-70.

-(2018c). Nuevas coyunturas entre extractivismos y desarrollo. Los límites del concepto de populismo y la deriva autoritaria. Ecuador Debate, 105: 23-45.

-(2018d). Disputas entre variedades de desarrollo y el cuadrilema de la globalización. En H. Cuevas, D.J. Véjar y J. Rojas (eds.), América Latina: expansión capitalista, conflictos sociales y ecológicos (pp. 173-191). Santiago de Chile: RiL Editores y Universidad de Concepción.

-(2019). Development and Nature. Modes of appropriation and Latin American extractivisms. En J. Cupples, M. Palomino-Schalscha y M. Prieto (eds.), The Routledge Handbook of Latin American Development (pp. 389-399). Londres: Routledge.

Harvey, D. (1975). The geography of capitalist accumulation: A reconstruction of the Marxian theory. Antipode, 72(1): 9-21.

- (2003). The New Imperialism, Oxford: Oxford University Press.

-(2004). El "nuevo" imperialismo: acumulación por desposesión. Socialist Register, 40: 99-129.

Hickel, J. y Kallis, G. (2020). Is Green Growth Possible? New Political Economy, 25(4), 469-485.

Hinkelammert, F.J. y Mora, H. (2009). Por una economía orientada hacia la reproducción de la vida. Íconos. Revista de Ciencias Sociales, 33: 39-49.

Hopkins, T. y Wallerstein, I. (1986). Commodity chains in the world economy prior to 1800. Review, 10(1): 157-170.

Infante-Amate, J., Urrego, A. y Tello, E. (2020). La venas abiertas de América Latina en la era del Antropoceno: un estudio biofísico del comercio exterior (1900-2016). Diálogos. Revista Electrónica de Historia, 21(2): 177-204.

Katz, C. (2015). Concepciones social-desarrollistas. Mundo Siglo XXI, revista del CIECAS-IPN, 10(35): 21-31.

Lander, E. (2019). Crisis civilizatoria. Experiencias de los gobiernos progresistas y debates en la izquierda latinoamericana. Guadalajara: CALAS.

Lópe, E. y Vértiz, F. (2015). Extractivism, Tansnational Capital, and Subaltern Struggles in Latin America. Latin American Perspectives, 42(5): 152-168.

Machado, H. (2013). Crisis ecológica, conflictos socioambientales y orden neocolonial: Las paradojas de NuestrAmérica en las fronteras del extractivismo. Revista Brasileira de Estudos Latino-Americanos, 3(1): 118-155.

- (2015). Crítica de la razón progresista. Una mirada marxista sobre el extractivismo/ colonialismo del siglo XXI. Aktuel Marx Intervenciones, 19: 137-173.

Mahnkopf, B. (2019). Geopolítica en el Capitaloceno. Papeles de relaciones ecolosociales y cambio global, 146: $35-45$.

Marini, R.M. (1977). La acumulación capitalista mundial y el subimperialismo. Cuadernos Políticos, 12: 2039.

- (1978). Las razones del neodesarrollismo (respuesta a F. H. Cardoso y J. Serra). Revista Mexicana de Sociología, 40(número extraordinario), 57-106.

Mazzucato, M. (2019). The Value of Everything. Making and Taking in the Global Economy. Londres: Penguin.

McKay, B.M. (2017). Agrarian Extractivism in Bolivia. World Development, 97: 199-211.

Merchand, M.A. (2016). Neoxtractivismo y conflictos ambientales en América Latina. Espiral. Estudios sobre Estado y Sociedad, 23(66): 155-192.

Muntané, J. (2017). Entrevista a Jason Moore: Del Capitaloceno a una nueva política ontológica. Ecología Politica. Cuadernos de debate internacional, 53: 108-110. 
Moore, Jason W. (2003a). Capitalism as world-ecology. Braudel and Marx on Environmental History. Organization \& Environment, 16(4): 431-458.

- (2003b). The Modern World-System as environmental history? Ecology and the rise of capitalism. Theory and Society, 32(3): 307-377.

- (2003c). Nature and the Transition from Feudalism to Capitalism. Review, 26(2): 97-162.

-(2013a). El auge de la ecología-mundo capitalista (I). Las fronteras mercantiles en el auge y decadencia de la apropiación máxima. Laberinto, 38: 9-26.

-(2013b). El auge de la ecología-mundo capitalista (II). Las fronteras mercantiles en el auge y decadencia de la apropiación máxima. Laberinto, 39: 21-29.

- (2014a). The Value of Everything? Work, Capital, and Historical Nature in the Capitalist World Ecology. Review, 37(3/4): 245-292.

-([2014b] 2017): El fin de la naturaleza barata: o cómoc aprendí a dejar de preocuparme por "el" medioambiente y amar la crisis del capitalismo. Relaciones Internacionales, 33: 143-174.

-(2015a). Capitalism in the Web of Life. Ecology and the Accumulation of Capital. Londres y Nueva York: Verso.

- (2015b). Nature in the limits to capital (and vice versa). Radical Philosophy, 193: 9-19.

- (2016). The Rise of Cheap Nature. En J.W. Moore (ed.), Anthropocene or Capitalocene? Nature, History, and the Crisis of Capitalism (pp. 78-115). Oakland: PM Press.

- (2017a). Value in the web of life, or, Why a world history matters to geography. Dialogues in Human Geography, 7(3): 326-330.

- (2017b). Metabolic rift or metabolic shift? dialectics, nature, and the world-historical method. Theory and Society, 46(4): 285-318.

-(2017c). The Capitalocene, Part I: on the nature and origins of our ecological crisis. Journal of Peasant Studies, 44(3): 594-630.

-(2018). The Capitalocene, Part II: on the nature and origins of our ecological crisis. Journal of Peasant Studies, 45(2): 237-279.

North, L.L. y Grinspun, R. (2016). Neo-extractivism and the new Latin American developmentalism: the missing piece of rural transformation. Third World Quarterly, 37(8): 1483-1504.

O'Connor, J. (1991). On the two contradictions of capitalism. Capitalism, Nature, Socialism, 2(3): 107-109.

Patel, R. y Moore, W.H. (2018). A History of the World in Seven Cheap Things. A Guide to Capitalism, Nature and the Future of the Planet. Carlton: Black Inc.

Pérez-Rincón, M. Vargas-Morales, J. y Martínez-Alier, J. (2019). Mapping and Analyzing Ecological Distribution Conflicts in Andean Countries. Ecological Economics, 157: 80-91.

Peters, S. (2016). Fin del ciclo: el neo-extractivismo en Suramérica frente a la caída de los precios de las materias primas. Un análisis desde una perspectiva de la teoría rentista. En H.J. Burchardt et al. (eds.), Nada dura para siempre. Neo-extractivismo tras el boom de las materias primas (pp. 21-54). Quito: Universidad Andina Simón Bolívar y Universität Kassel.

Petras, J. y Veltmeyer, H. (2014). Extractive Imperialism in the Americas. Capitalism's New Frontier. Leyden y Boston: Brill.

-(2016). Power and Resistance. US Imperialism in Latin America. Leyden y Boston: Brill.

Puyana, A. (2017). El retorno del extractivismo en América Latina. ¿Ruptura o profundización del modelo de economía liberal y por qué ahora? Espiral. Estudios de Estado y Sociedad, 24(69): 73-113.

Robinson, W.I. (2019). Global Capitalist Crisis and Twenty-First Century Fascism: Beyond de Trump Hype. Science \& Society, 83(2): 481-509.

Rodríguez, I. et al. (2019). Conflictividad socioambiental en América Latina. Aportes de las transformación de conflictos socioambientales a la transformación ecológica. Cuadernos de la Transformación, 3.

Samaniego, P., Vallejo, M.C. y Martínez-Alier, J. (2017). Commercial and biophysical déficits in South America, 1990-2013. Ecological Economics, 133: 62-33. 
Savoia, A. y Sen, K. (2020). The political economy of the "resource curse". A development perspective. WIDER Working Paper, 2020/123.

Scheidel, A. et al. (2018). Ecological distribution conflicts as forces for sustainability: an overview and conceptual framework. Sustainability Science, 13(3): 585-598.

Schuldt, J. y Acosta, A. (2006). Petróleo, rentismo y subdesarrollo ¿Una maldición sin solución? Nueva Sociedad, 206: 71-89.

Sullivan, S. (2013). Banking Nature? The Spectacular Financialisation of Environmental Conservation. Antipode, 45(1): 198-217.

Svampa, M. (2012). Consenso de los Commodities, Giro Ecoterritorial y Pensamiento crítico en América Latina. Observatorio Social de América Latina, 13(32): 15-38.

- (2013). Consenso de los Commodities y lenguajes de valoración en América Latina. Nueva Sociedad, 244 : $30-46$.

-(2019). Las fronteras del neoextractivismo en América Latina. Conflictos socioambientales, giro ecoterritorial y nuevas dependencias. Buenos Aires: UNSAM.

Svampa, M. y Teran, E. (2019). En las fronteras del cambio de época. Escenarios de una nueva fase del extractivismo en América Latina. En K. Gabbert y M. Lang (eds.), Cómo se sostiene la vida en América Latina? Feminismos y re-existencias en tiempos de oscuridad (pp.169-219). Quito: Fundación Rosa Luxemburg / Ediciones Abya-Yala.

Teran, E. (2016). Las nuevas fronteras de las commodities en Venezuela: un salto del extractivismo en el "tejido de la vida". Ecología Politica. Cuadernos de debate internacional, 51: 60-65.

Veltmeyer, H. (2013). The Political Economy of Natural Resource Extraction: A New Model or Extractive Imperialism. Canadian Journal of Development Studies, 34(1): 85-92.

Vernengo, M. (2018). ¿La "trampa del ingreso medio" o el retorno de la hegemonía estadounidense? Coyuntura y Desarrollo, 385: 171-178.

Walker, R. y Moore, J.W. (2019). Value, Nature, and the Vortex of Accumulation. En H. Ernstson and E. Swyngedouw (eds.), Urban Political Ecology in the Anthropo-Obscene (pp. 48-68). Nueva York: Routledge.

Wanderly, F. Vera, H. y Benavides, J.P. (2019). Las paradojas del desarrollo andino-amazónico en el siglo XXI: crecimiento extractivista, logros sociales y pérdida de patrimonio ambiental Estudios Críticos del Desarrollo, 9(17): 197-142.

Ye, J. et al. (2020). The incursions of extractivism: moving from dispersed places to global capitalism. Journal of Peasant Studies, 47(1): 155-183. 